\title{
Electrophysiological Evidence for the Development of a Self-Sustained Large-Scale Epileptic Network in the Kainate Mouse Model of Temporal Lobe Epilepsy
}

\author{
Laurent Sheybani, ${ }^{1,2}$ Gwenaël Birot, ${ }^{2}{ }^{\circledR}$ Alessandro Contestabile, ${ }^{3}$ Margitta Seeck, ${ }^{2}$ Jozsef Zoltan Kiss, ${ }^{3}$ Karl Schaller, ${ }^{4}$ \\ Christoph M. Michel, ${ }^{1,2,5 *}$ and $\mathbb{C}^{-C h a r l e s}$ Quairiaux ${ }^{1,3 *}$ \\ ${ }^{1}$ Functional Brain Mapping Laboratory, Department of Fundamental Neuroscience, Campus Biotech, University of Geneva, 1202 Geneva, Switzerland, \\ ${ }^{2}$ Neurology Clinic, Department of Clinical Neuroscience, University Hospital Geneva, 1206 Geneva, Switzerland, ${ }^{3}$ Department of Fundamental \\ Neuroscience, Faculty of Medicine, 1206 Geneva, Switzerland, ${ }^{4}$ Neurosurgery Clinic, Department of Clinical Neuroscience, University Hospital Geneva, 1206 \\ Geneva, Switzerland, and ${ }^{5}$ Center for Biomedical Imaging, Lausanne and Geneva, 1015 Lausanne, Switzerland
}

Most research on focal epilepsy focuses on mechanisms of seizure generation in the primary epileptic focus (EF). However, neurological deficits that are not directly linked to seizure activity and that may persist after focus removal are frequent. The recruitment of remote brain regions of an epileptic network (EN) is recognized as a possible cause, but a profound lack of experimental evidence exists concerning their recruitment and the type of pathological activities they exhibit. We studied the development of epileptic activities at the large-scale in male mice of the kainate model of unilateral temporal lobe epilepsy using high-density surface EEG and multiple-site intracortical recordings. We show that, along with focal spikes and fast ripples that remain localized to the injected hippocampus (i.e., the $\mathrm{EF}$ ), a subpopulation of spikes that propagate across the brain progressively emerges even before the expression of seizures. The spatiotemporal propagation of these generalized spikes (GSs) is highly stable within and across animals, defining a large-scale EN comprising both hippocampal regions and frontal cortices. Interestingly, GSs are often concomitant with muscular twitches. In addition, while fast ripples are, as expected, highly frequent in the $\mathrm{EF}$, they also emerge in remote cortical regions and in particular in frontal regions where GSs propagate. Finally, we demonstrate that these remote interictal activities are dependent on the focus in the early phase of the disease but continue to be expressed after focus silencing at later stages. Our results provide evidence that neuronal networks outside the initial focus are progressively altered during epileptogenesis.

Key words: awake recordings; electrophysiology; epilepsy; high-frequency oscillations; interictal epileptic discharges; large-scale networks

Significance Statement

It has long been held that the epileptic focus is responsible for triggering seizures and driving interictal activities. However, focal epilepsies are associated with heterogeneous symptoms, calling into question the concept of a strictly focal disease. Using the mouse model of hippocampal sclerosis, this work demonstrates that focal epilepsy leads to the development of pathological activities specific to the epileptic condition, notably fast ripples, that appear outside of the primary epileptic focus. Whereas these activities are dependent on the focus early in the disease, focus silencing fails to control them in the chronic stage. Thus, dynamical changes specific to the epileptic condition are built up outside of the epileptic focus along with disease progression, which provides supporting evidence for network alterations in focal epilepsy.

\section{Introduction}

Focal epilepsies are defined by the recurrence of seizures and interictal epileptic discharges (IEDs) in a restricted brain region called the epileptic focus (EF). However, remote structural and functional alterations have been shown in humans (Kobayashi et al., 2006; Bonilha et al., 2010; Coito et al., 2015) and animal models 
of focal epilepsy (Kleen et al., 2010; Gelinas et al., 2016). While these observations support the hypothesis that regions remote from the EF could be recruited as part of a large-scale epileptic network (EN) (Spencer, 2002; Richardson, 2012; Goodfellow et al., 2016), our knowledge of the development, extent, and electrophysiological signature of such networks in focal epilepsies remains sparse.

In addition, the process by which an initial insult leads to the onset of seizures (epileptogenesis) can take weeks to years in humans. It is therefore challenging to capture the many pathological processes that are induced in the brain during early epileptogenesis. However, defining the developmental timing and extent of the remote pathological activities in focal epilepsies is of utmost importance. For example, the emergence of a large-scale EN might contribute to the persistence of abnormal network activities after complete surgical resection of the preoperatively identified focus (Van Schooneveld and Braun, 2013).

In the present work, we used the well-established kainate mouse model of temporal lobe epilepsy (TLE) to investigate whether the induction of a focal epilepsy leads to the development of a largescale EN extending further than the seizure onset zone, and to characterize this network electrophysiologically. In the kainate mouse model of TLE, a unilateral localized kainate injection in the dorsal hippocampus induces a status epilepticus followed by neuronal degeneration and gliosis in the dorsal CA1, CA3, and dentate gyrus of the ipsilateral but not the contralateral hippocampus (Suzuki et al., 1995; Bouilleret et al., 1999; Riban et al., 2002; Arabadzisz et al., 2005; Heinrich et al., 2006; Langlois et al., 2010; Twele et al., 2017). As in human TLE, a latent period follows a precipitating event, such as febrile seizures in infants, and precedes the development of recurrent spontaneous paroxysmal discharges that are reminiscent of focal seizures and that remain localized to the sclerotic hippocampus.

Using combined high-density EEG and multiple intracerebral recordings along with video-based behavioral assessment of epileptic activity in awake animals, we performed a systematic investigation of the development of the epileptic disease in the unilateral TLE mouse model at the level of large-scale networks. During the latent phase of the disease, along with the classical focal spikes that remained localized to the injected hippocampus, other IEDs appeared that propagated beyond the EF in an epileptic network comprising both the sclerotic and the contralateral hippocampus, and extending into frontal neocortical regions. These propagating IEDs, called generalized spikes (GSs), evoked transient motor symptoms, which may be associated with their propagation pattern toward frontal motor regions. GSs were not seen in control recordings before the kainate injection or in salineinjected animals. Such large-scale pathological waves have been detected in human TLE and were associated with a poor prognosis (Aarts et al., 1984; Mohamed et al., 2001; Moseley et al., 2012; Pittau et al., 2013). Furthermore, we reveal that pathological fast ripples (FRs) are expressed in the EF and also in remote areas, which contrasts with previous work that described these events as

reviewing previous versions of the paper; Dr. Serge Vulliemoz and Dr. Francesca Pittau for help with interpreting surface EEG; Dr. Ilaria Vitali and Riccardo Bocchi for constructive feedback and technical help during the study; and Dr. Marc Goodfellow for help in the final redaction of the manuscript.

The authors declare no competing financial interests.

* C.M.M. and C.Q. contributed equally to this work as co-senior authors.

Correspondence should be addressed to Dr. Charles Quairiaux, Functional Brain Mapping Laboratory, Department of Fundamental Neuroscience, Centre Médical Universitaire, 1 rue Michel-Servet, 1206 Genève, Switzerland. E-mail: charles.quairiaux@unige.ch.

DOI:10.1523/JNEUROSCI.2193-17.2018

Copyright $\odot 2018$ the authors $\quad 0270-6474 / 18 / 383777-16 \$ 15.00 / 0$

\section{Table 1. Experimental procedures and animals}

Electrophysiological groups

1. Surface EEG recordings from preinjection (control) to D7, D14, and D28

a. Longitudinal recordings prekainate and postkainate: 30 animals

12 animals recorded at every time point +18 animals recorded prekainate and/or at D28 postkainate. $N$ recordings for:

- Unpaired analyses: 23 preinjection controls, 12 D7, 12 D14, 21 D28

- Paired analyses: 12 at every time points

b. Sham experiments: 4 kainate-injected (included in a) and 4 saline-injected animals 2.Silencing of the EF

3 animals at D7 and 6 at D28 postkainate (4 animals from group 1.a +5 additional animals)

3. Intracerebral EEG recordings (iEEG) at D28

8 kainate-injected animals ( 2 animals from group $1 . a+6$ additional animals)

4 saline-injected animals (from 1.b)

4. Combined surface-intracerebral EEG recordings (EEG-iEEG) at D28

6 kainate-injected animals (from 1.a)

5.Surface EEG recordings with video monitoring at D28

15 kainate-injected animals (from 1.a)

Histopathology groups

6. Analyses during the latent phase at D2 and D7

12 kainate-injected animals: 6 analyzed at $D 2$ and 6 at $D 7$

8 saline-injected animals: 4 analyzed at D2 and 4 at D7

7. Analyses during the chronic phase (D28)

21 kainate- and 4 saline-injected animals (from 1)

specific to the EF (Jacobs et al., 2010; Staba, 2012; Zijlmans et al., 2012; Menendez de la Prida et al., 2015).

Using pharmacological silencing of the focus, we then show that GS and remote FRs are suppressed by silencing the EF in the early stage but not in the chronic stage of the disease, which experimentally validates the progressive emergence of self-sustaining pathological activities outside of the EF. These results shed light on the extrafocal alterations emerging in the aftermath of EF induction, which cannot be ignored if one wishes to study epileptogenesis in its full complexity. Further research will be needed to better understand the role of these extrafocal alterations in the development of neurological deficits and ictogenesis.

\section{Materials and Methods}

Animals

Sixty-five male C57BL/6j mice (Charles River) were included in this study. Recordings made before kainate injections (D-1) were used as internal controls for surface EEGs. Saline-injected animals were used as a sham control group and were subject to the same procedure as kainate-injected animals (for a complete description of the experimental groups, see Table 1). All experiments were conducted in accordance with Swiss Laws on animal experimentation. Table 1 displays the number of animals used for every experiment. A total of 65 animals were used in this study. Some animals were included in several experimental groups. For the longitudinal surface EEG experiments from preinjection to $28 \mathrm{~d}$ after the injection, we used 30 kainate-injected animals. However, not all animals could be recorded at every time point (i.e., preinjection, D7, D14, and D28 postinjection) for technical reasons (malfunction or loss of the head-holder, or death of the animal). Therefore, we made unpaired analyses (with the time-wise recordings made in all 30 kainate-injected animals) and paired analyses (with the recordings made in the 12 animals recorded at all time points). The 4 sham saline-injected animals were also recorded at every time point. In addition, 10 supplementary kainateinjected animals died prematurely ( 5 during the injection surgical procedure or the first $24 \mathrm{~h}$ postinjection and 5 others during the following days) and were not included in the study.

\section{Surgery}

Head-holder. Surgeries were performed under isoflurane anesthesia (induction $2.5 \%$, maintenance $1 \%-1.5 \%$ ). Animals were mounted in a ste- 
reotaxic frame, and their temperature was monitored with a rectal probe connected to a closed-loop heating pad. The skin was retracted, and the positions of the epicranial electrodes were marked by gently applying the electrode grid stained with blue ink on the skull surface. The skull was covered by a thin layer of Loctite (Henkel) and once dry, a small patch (500 $\mu \mathrm{m}$ in diameter) of the Loctite layer was removed with a drill at each electrode location. An aluminum ring-like head-holder was fixed with dental cement on the occipital and nasal bones. The center of the ring was filled with silicon (Kwik-Cast, World Precision Instrument) before the animals were brought back to their cage. Animals were transiently put under a heating lamp until they awoke. Antibiotics (trimethoprime-sulfamethoxazole, Roche) and anti-inflammatory analgesic (Ibuprofene, Vifor, and Paracetamol, BristolMyers) were added to their drinking water. Mice were allowed to recover for $3 \mathrm{~d}$ before training for head-fixation began.

Kainate and saline injections. We used the kainate mouse model of unilateral TLE as described previously (Riban et al., 2002; Arabadzisz et al., 2005). Kainate or saline solutions were injected 1 week after head-holder surgeries. Under isoflurane anesthesia, a $0.3 \mathrm{~mm}$ hole was drilled above the dorsal left hippocampus ( $\mathrm{LH}$; mediolateral $1.6 \mathrm{~mm}$, anteroposterior -1.8 $\mathrm{mm}$, depth $1.9 \mathrm{~mm}$ ). Using the Nanoinject device (Drummond), a volume of $70 \mathrm{nl}$ of kainic acid (Tocris Bioscience; $5 \mathrm{~mm}$ in $\mathrm{NaCl} 0.9 \%$ ) or saline was then injected with a pulled glass capillary (Drummond glass capillaries \# 3-000-203 $\mathrm{G} / \mathrm{X}$; tip diameter $\sim 15 \mu \mathrm{m}$ ) inserted through the neocortex up to the dorsal $\mathrm{LH}$ at a speed of $46 \mathrm{nl} / \mathrm{s}$. The capillary was left in position for $2 \mathrm{~min}$ after the injection. The skull was cleaned with Betadine, and a new silicon cap was introduced. Antibiotics and anti-inflammatory analgesics were provided for $3 \mathrm{~d}$ as described above. Brain histopathological analyses using Nissl-stained and cresyl violet Luxol fast blue coronal sections were performed as previously described (Quairiaux et al., 2010) in all animals at the end of the experiment to check for the presence of hippocampal sclerosis. Large-scale Nissl and Fluoro-jade stainings were also performed in a group of animals 2 and $7 \mathrm{~d}$ after kainate or saline injection to exclude the possibility that the early status epilepticus or diffusion of kainate might trigger structural changes and neuronal death outside the injected hippocampus (for detailed histological procedures, see Sizonenko et al., 2008).

Epileptic focus silencing. TTX injections were used to silence the LH (i.e., the epileptic focus) as previously described (Cowansage et al., 2014). A volume of $0.15 \mu \mathrm{l}$ of TTX (Sigma-Aldrich; $0.3 \mathrm{~mm}$ in $\mathrm{NaCl} 0.9 \%$ ) was injected in the dorsal LH (anteroposterior -2.67 , mediolateral 2.5, depth 1.72 and $1.22 \mathrm{~mm}$, angle $20^{\circ}$ ) using the Nanoinject as described above.

\section{Video-based behavioral analysis}

Surface EEGs were collected under video monitoring ( 25 frames/s), similarly to long-term EEG monitoring in humans. To quantify animal movements during GS, movies were converted into black-and-white images. We used images from 15 of the 21 animals that had surface EEG at D28: the movies of 6 animals were discarded because of poor image quality during the acquisition. Then, pixel-intensity variations were measured between each successive time frame for all pixels of the images (|Pixel $\times$ time frame $n+1-$ Pixel $\times$ timeframe $n \mid$; see Fig. 5). To estimate global movement, we calculated a visual motion index (VMI) at each time frame by averaging differences in pixel-light intensities across pixels. The absolute difference of light intensity from one timeframe to another is equal to zero when no movement is detected, whereas it increases in regions of the image in which movement occurs (see Fig. 7).

\section{Intracortical EEG}

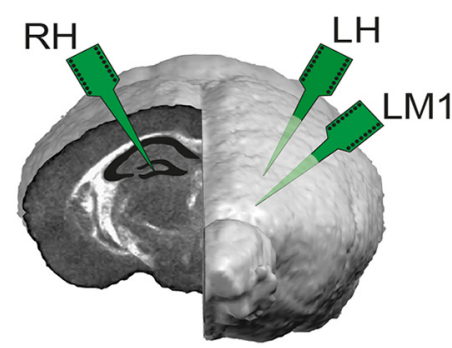

\section{Combined EEG-iEEG}

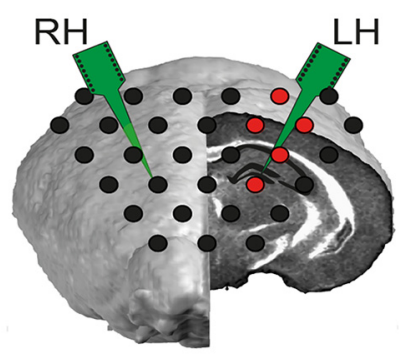

This index was averaged across periods before $(-540 \mathrm{~ms}$ to $-40 \mathrm{~ms})$, and
during/after ( -20 to $800 \mathrm{~ms})$ GSs to calculate the VMI ratio [after: before]. To allow for statistical comparisons with control periods, the same procedure was performed during baseline EEG with a number of randomly set markers equivalent to the number of GSs.

\section{Head-fixed recordings and analysis}

The presence of paroxysmal hippocampal discharges, IEDs, and FRs was monitored during head-fixed recording sessions before (D-1 controls) and 7, 14, and $28 \mathrm{~d}$ after kainate or saline injections. Recording sessions lasted $20 \mathrm{~min}$ for surface EEG; $30 \mathrm{~min}$ for EEG silencing experiments and 50 min for intracerebral EEG (iEEG) and combined EEG-iEEG. Animals were trained to remain head-fixed twice a day during $3 \mathrm{~d}$ before the recording sessions. Durations were progressively increased up to the duration of the recording sessions, starting with $10 \mathrm{~min}$. To position the animal in the headfixed apparatus, it was lightly anesthetized using isoflurane (maximum $0.8 \%$ ) both for the training and the recording sessions. This allowed precise positioning of surface and intracerebral electrodes. After removal of anesthesia, we waited for the animal to be fully awake, or at least 10 min, before beginning the recordings.

As illustrated in Figure 1, surface EEGs were recorded with 32 stainlesssteel electrodes $(500 \mu \mathrm{m} \varnothing)$ covering the entire skull surface as described previously (Mégevand et al., 2008; Quairiaux et al., 2011). iEEGs were recorded with 3 Neuronexus A16 probes implanted in both hippocampi and in the frontal cortex (anteroposterior and mediolateral coordinates relative to bregma and depth in $\mathrm{mm}$ and angles: $\mathrm{LH}:-2.67,2.5,2.02,20^{\circ}$; right hippocampus $(\mathrm{RH}):-2.67,-2.5,2.02,20^{\circ}$; left primary motor cortex: $1.3,1.2,0.9,6^{\circ}$ in 4 animals and $1.3,2.3,0.9,25^{\circ}$ in 3 animals). The $\theta$ activity was highest between 1.52 and $1.82 \mu \mathrm{m}$ (i.e., at the level of the hippocampal fissure and hilus) in agreement with a previous report (Buzsáki et al., 2003). Combined surface EEG-intracerebral EEG (EEGiEEG) was recorded with 32 surface channels together with 2 Neuronexus A16 probes in $\mathrm{RH}$ and $\mathrm{LH}$ (same coordinates as above). Surface (sampling rate: $4 \mathrm{kHz}$, low-pass $2 \mathrm{kHz}$ ) and intracerebral (sampling rate: 16 $\mathrm{kHz}$, low-pass $8 \mathrm{kHz}$ ) recordings were acquired with a Digital Lynx SX (Neuralynx). Electrophysiological data were analyzed with Cartool (D. Brunet, Center for Biomedical Imaging, University of Geneva, Switzer- 

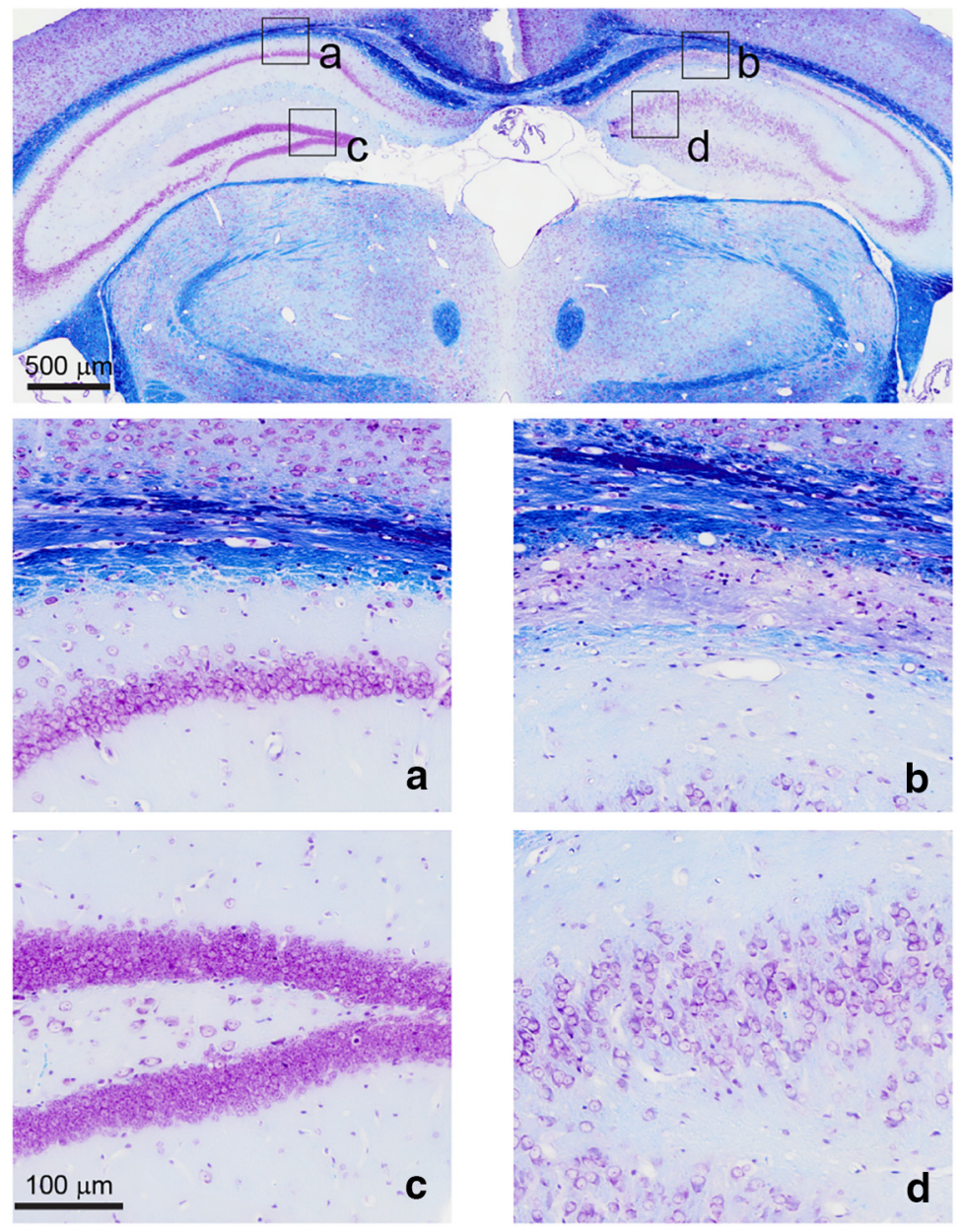

Figure 2. Illustrative cresyl violet and Luxol fast blue section of the brain showing the morphology of both hippocampi $28 \mathrm{~d}$ following intrahippocampal kainate injection in the left hippocampus. The pyramidal layer in the noninjected $(\boldsymbol{a})$ and injected $(\boldsymbol{b})$ hippocampi as well as the granule cells layer in the noninjected $(\boldsymbol{c})$ and injected $(\boldsymbol{d})$ hippocampi are magnified.

land) and MATLAB software (The MathWorks) as detailed below. Multiunit activity (Fig. 11) was identified using threshold detection, following the Quiroga method (Quiroga et al., 2004).

IEDs. Two types of IEDs were detected on surface EEGs. Focal spikes were characterized by isolated large positive deflections with riding FRs (Fig. 11C). GSs were easily identified as interictal discharges that invaded all electrodes with 2 peaks of high-amplitude deflections lasting between 30 and $40 \mathrm{~ms}$ and separated by a flattening of the EEG of $\sim 250 \mathrm{~ms}$. EEG periods were systematically extracted from recordings and presented to a coauthor (C.Q.) blinded to the animal condition (prekainate, kainate and salineinjected animals). GSs were reliably identified in kainate-injected animals but not in controls during blind reviews.

GSs were analyzed using topographic methods as used for human EEG (Lantz et al., 2003; Michel et al., 2004). The GS start was first set at the maximum of the absolute value (either positive or negative) of the first peak across all electrodes; then GS statistical onset was calculated at each electrode as the first time-frame that passed a $5 \mathrm{SD}$ threshold of the absolute value of the baseline, which was calculated from the $950 \mathrm{~ms}$ period before the GS start. GS statistical onset was defined by the electrode presenting the earliest above-threshold activity. To identify whether a sequence of potential maps could be sorted out of the data, we followed a 2-step analyses described previously (Mégevand et al., 2008). First, in each animal, GSs were averaged by aligning the EEG to their statistical onset (see above). Thus, we obtained for each animal one individual GS. These GSs were averaged to obtain a grand-average GS. Then, a topographic hierarchical clustering algorithm was applied to the grand-averaged GS across animals (Mégevand et al., 2008; Brunet et al., 2011) to identify the dominant potential maps that best explain the EEG.
Second, to check whether this sequence of maps was shared among mice, we back-fitted the maps over the individual GS of each animal and determined their mean latency, estimated by their timeframe at best correlation along GS (i.e., topographical correlation between a map and a GS timeframe). In Figure 12D, to test the TTX-induced loss of LH activity during GS, we compared the individual average voltage amplitude during the first peak of GS at electrodes specific for the LH region in a group of 6 animals before and during TTX silencing (paired $t$ test, Bonferroni-corrected).

The global field power, used to estimate the intensity of the GS on a large-scale level, corresponds to the spatial SD of all electrode voltage values and represents the activity strength of the potential field (Lehmann and Skrandies, 1980). The formula is as follows:

$$
G F P=\sqrt{\frac{\sum_{i=1}^{n}\left(v_{i}-\bar{v}\right)^{2}}{n}}
$$

where $n$ is the number of electrodes, $v$ the voltage measured at electrode $i$ and $\bar{v}$ is the mean potential across electrodes.

For combined EEG-iEEG, intracerebral data were aligned to the surface GS onsets and current-source density were calculated for each epoch using the second spatial derivative of the electrical potential (Mégevand et al., 2008) defined by the following:

$$
C S D=\frac{V_{h-\Delta h}-2 \cdot V_{h}+V_{h+\Delta h}}{\Delta h^{2}}
$$

where $V$ is the potential at position $h$ and $\Delta h$ is the distance between electrodes.

Hippocampal paroxysmal discharge (HPD) identification. Epileptic discharges comparable with events that were termed paroxysmal hippocampal discharges, focal seizures, or seizurelike events in previous publications with the kainate mouse model (Bouilleret et al., 1999; Riban et al., 2002; Langlois et al., 2010; KrookMagnuson et al., 2013; Paz et al., 2013; Twele et al., 2017) were identified in the surface EEG or iEEG signals using the same detection criterions previously described (Krook-Magnuson et al., 2013; Paz et al., 2013) based on spike features and frequency power properties. Briefly, electrographic seizures-like events were characterized by sustained sharp rhythmic spikes with amplitudes exceeding the preceding baseline EEG by a least 2 SD and lasting $>5 \mathrm{~s}$. Regularity and rhythmicity of discharges, as well as constancy of an electrical dipole for intracortical recordings, allow differentiating epileptic spikes from movements' artifacts. Artifacts typically occurring during grooming or chewing presented narrow spikes characteristically separated by $<50 \mathrm{~ms}$ and irregular in shape and amplitudes. Hippocampal paroxysmal discharges were also characterized by the increased power in alpha activity that extended into the theta band and simultaneously by an increase in the highest frequency oscillations $\sim 200-250 \mathrm{~Hz}$ (see Fig. $4 A$ ). These activities had to last for a minimum of $5 \mathrm{~s}$ to minutes and remain localized to a discrete brain region. We then used video monitoring to check that those detected seizures-like events were not concomitant of movements, such as those seen during grooming, chewing, or scratching. Finally, HPDs were confirmed by a blinded reviewer (C.Q.). In Figure 4, time-frequency plots were obtained through a normalized (i.e., $z$-scored) short-time Fourier transform of the epoch $(2 \min 50 \mathrm{~s})$.

FR identification. To standardize the identification of FRs and to avoid any examiner bias, we developed an automatic detector of FRs based on criteria provided in the literature (Bragin et al., 1999; Lévesque et al., 


\section{A Dorsal hippocampi at D2}
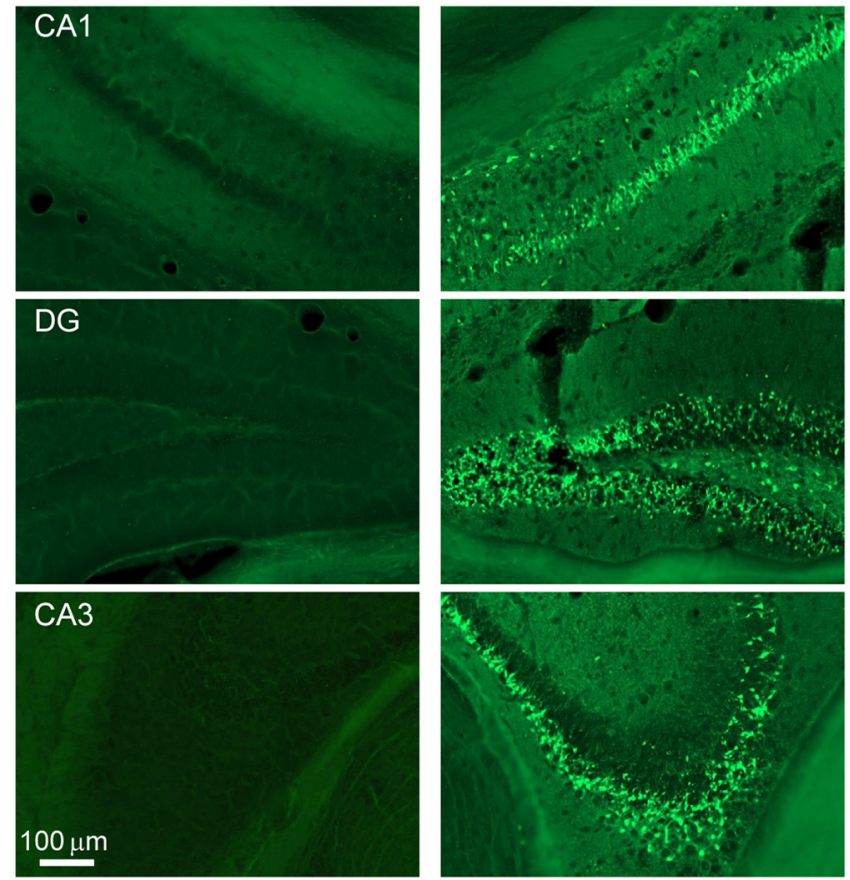

\section{Frontal cortices at D2}

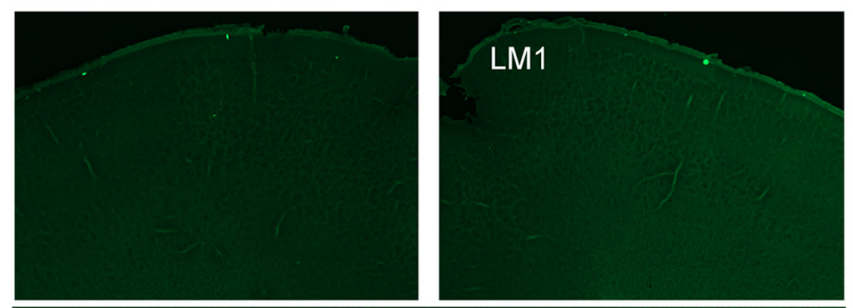

$\mathrm{CC}$
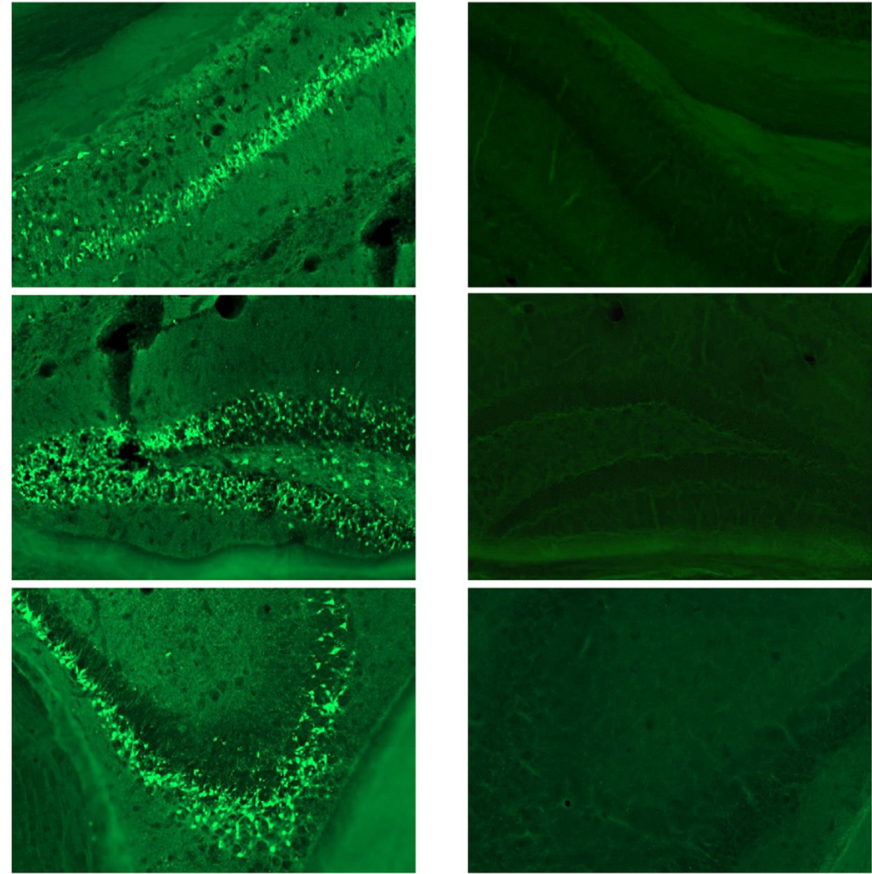

\section{Frontal cortices at D7}

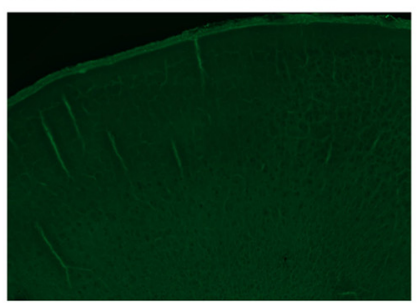

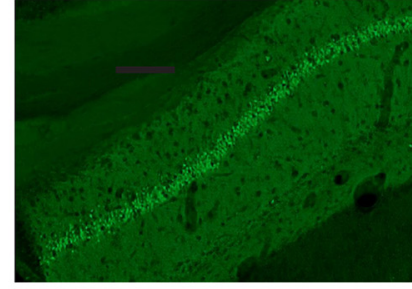
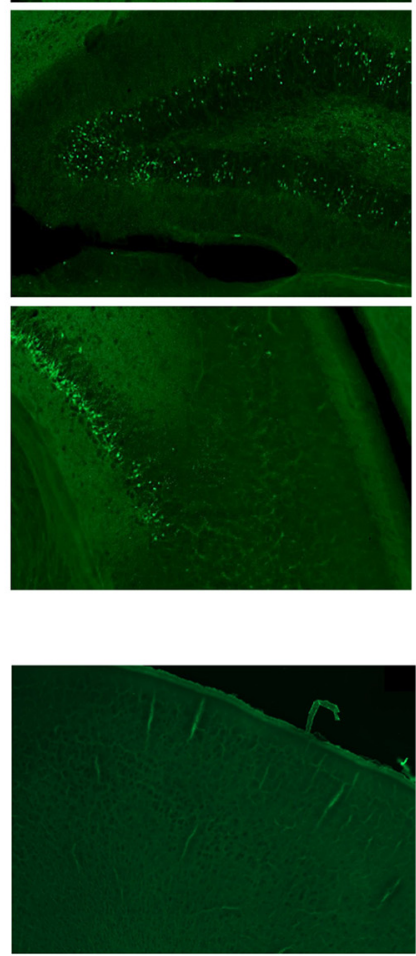
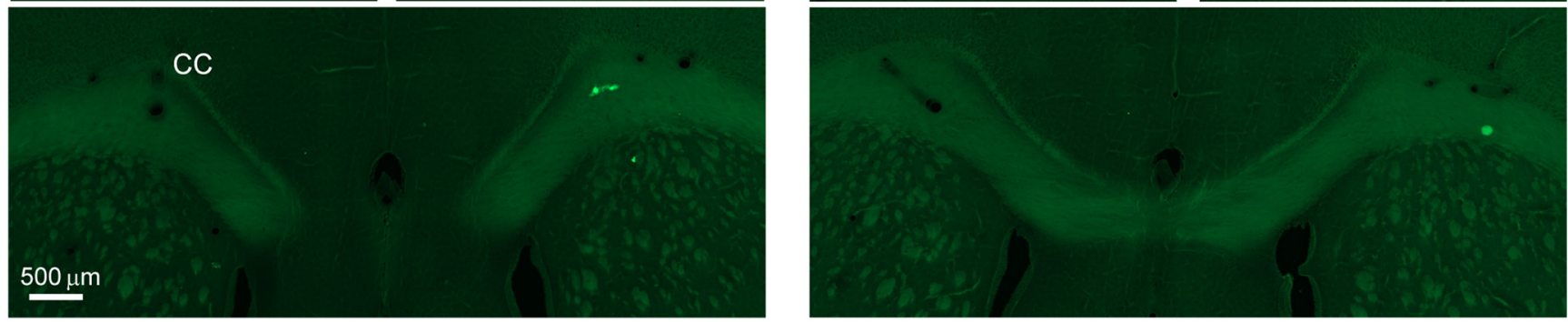

Figure 3. Large-scale structural analysis during the latent phase. $A$, Representative Fluoro-jade-stained sections at the level of the dorsal hippocampus $2 \mathrm{~d}$ after kainate injection. Fluoro-jade-labeled neurons are visible in the pyramidal layer of CA1 and CA3 and in the DG of the injected LH (right), whereas no labeled cells are observed in the contralateral noninjected RH (left). $\boldsymbol{B}$, Representative Fluoro-jade-stained sections at the level of the dorsal hippocampus $2 \mathrm{~d}$ after kainate injection. Fluoro-jade staining is less strong than at $\mathrm{D} 2$ because the process of cell death has decreased $7 \mathrm{~d}$ after kainate injection. $\boldsymbol{C}, \boldsymbol{D}$, Fluoro-jade-stained sections at the level of the frontal motor cortex in the same animals as in $\boldsymbol{A}$ and $\boldsymbol{B}$, respectively (i.e., at D2 and D7). No Fluoro-jade-labeled neurons are visible in the right and left frontal cortices. Similar observations were made in other neocortical regions in all kainate-injected animals animals at D2 and D7 ( $n=6$ at both ages).

2011). It identifies events with $\geq 4$ consecutive oscillations 3 times higher in amplitude than the SD of the $\pm 250 \mathrm{~ms}$ surrounding baseline. Before screening, data were filtered between 200 and $550 \mathrm{~Hz}$ using an order 2 Butterworth filter. All identified events were visually confirmed in the filtered and unfiltered data (Bénar et al., 2010). To prevent the harmonics of lower frequencies from being identified as FRs, we kept only FRs that did not coincide with ripples or high-gamma activity of a higher intensity. Based on phase-lag differences, we further eliminated FRs at multiple contacts that could be explained by volume conduction. Indeed, if no phase lag is measured between two events identified at two different positions, one could assume that one of the two events is due to volume conduction. Thus, when this occurred, we retained only one event (i.e., the one with the highest power). The duration of FRs was calculated as the time between the first and last oscillations above the threshold. The intrinsic frequency was the peak frequency (Fourier transform) within $200-550 \mathrm{~Hz}$ of each event. The power of FRs was calculated as the sum of the absolute squares of each event (normalized for the duration of the FR).

\section{Experimental design and statistical analysis}

Statistical analyses were performed using Prism (GraphPad Software) and MATLAB. The normality of data distributions was evaluated with the D'Agostino-Pearson test before proceeding to statistical tests: $t$ test (two groups, normal distribution), Mann-Whitney (two groups, nonparametric distribution unpaired groups), Wilcoxon (two groups, nonparametric distribution paired groups), ANOVA ( $>2$ groups, normal 


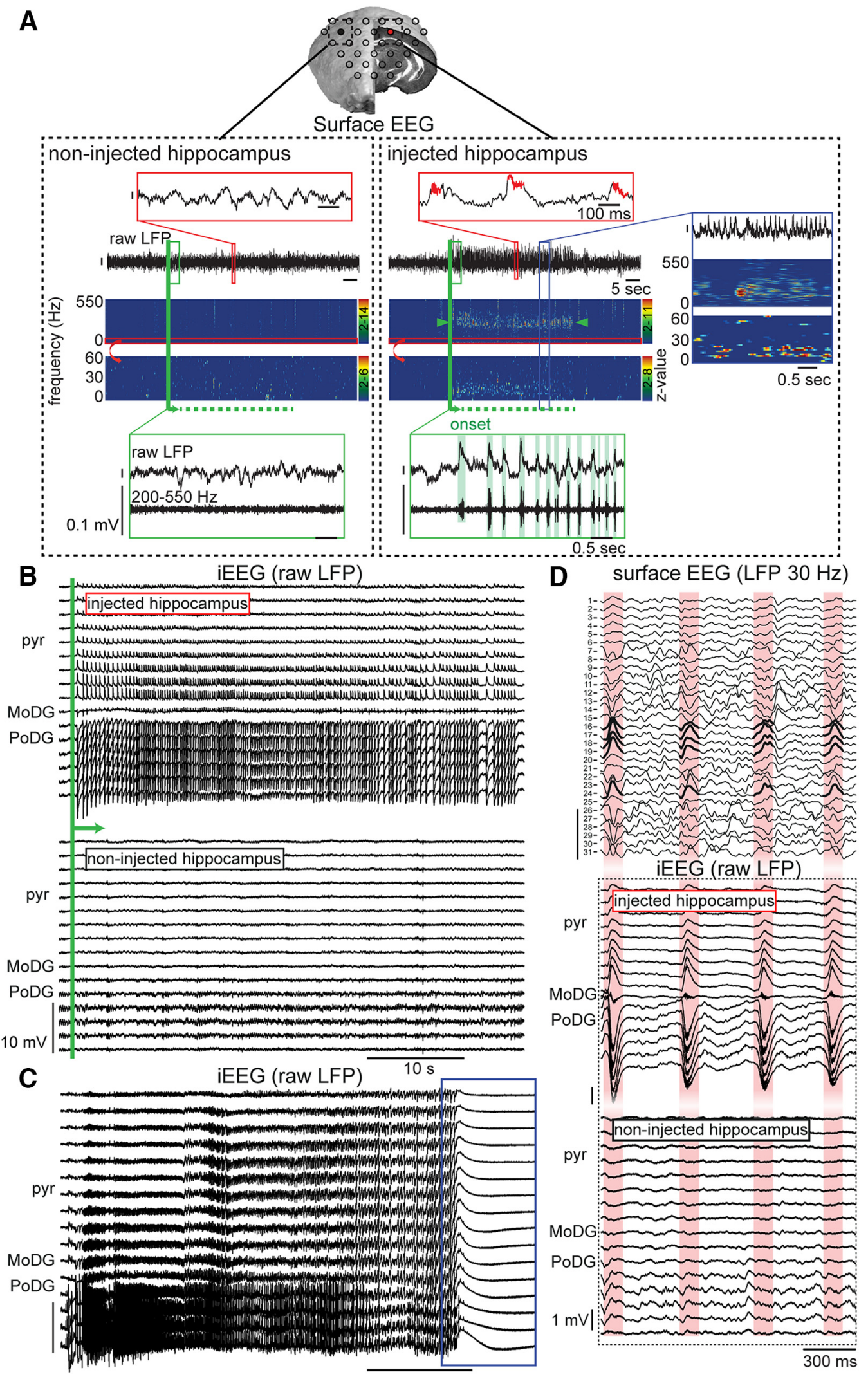

Figure 4. Operational definition of paroxysmal HPDs. A, Example of a whole train of paroxysmal hippocampal discharges, reminiscent of an epileptic seizure, recorded with surface EEG, beginning around the green vertical line and lasting $\sim 41 \mathrm{~s}$ as indicated by the green dashed lines. Raw signals are shown from simultaneous recordings from an electrode located over the injected hippocampus (electrode e19, see Fig. 1, top, red) and an electrode over the contralateral noninjected hippocampus (electrode e5, see Fig. 1, black). Bottom, Corresponding time-frequency plots across the $0-550 \mathrm{~Hz}$ spectrum (top) and centered on the frequency of epileptic spikes (i.e., $0-60 \mathrm{~Hz}$ ), which corresponds to the red square in the above time-frequency decomposition. Note the increased activity in the frequency band of epileptic spikes $(15-30 \mathrm{~Hz})$ and FRs $(200-550 \mathrm{~Hz})$. Right, Blue rectangle represents an expanded view of a $4 \mathrm{~s}$ period of the seizure to better illustrate its structure. Top, Red rectangles represent a $1 \mathrm{~s}$ magnification of the raw signal for both electrodes with 3 spikes and superimposed FRs (highlighted in red) visible (Figure legend continues.) 
distribution; post hoc: Tukey's multiplecomparison test), Kruskal-Wallis ( $>2$ groups, nonparametric distribution unpaired groups; post hoc: Dunn's multiple-comparison test) and Friedman ( $>2$ groups, nonparametric distribution, paired groups; post hoc: Dunn's multiple-comparison test). The alpha threshold was set to 0.05 . The Spearman test was used for nonparametric analyses of correlation. For the analyses of the evolution of epileptic activities across time (see Fig. 5), unpaired as well as paired and longitudinal designs were used; details are given in appropriate subsections of Results.

\section{Results}

Large-scale recordings of a focal disease Focal epilepsies are identified by the existence of seizures starting from one specific brain region (i.e., the EF). Here, we studied functional deficits at the level of largescale networks in focal epilepsy using the kainate mouse model of TLE, in which a focal lesion is induced unilaterally in the dorsal hippocampus. It has been demonstrated that intrahippocampal kainate injection leads to a focal disease as defined by localized lesions and paroxysmal discharges or seizure-like events in the injected hippocampus, whereas the ventral hippocampus and the contralateral side remain unaltered and do not express paroxysmal discharges (Riban et al., 2002; Arabadzisz et al., 2005; Heinrich et al., 2006; Ledergerber et al., 2006; Rattka et al., 2013). To investigate the disease at the large scale, we used acute recording sessions (20-50 min) with surface EEG covering the entire dorsal skull surface, intracerebral EEG simultaneously in both hippocampi and frontal cortical regions as well as combined bihippocampal intracerebral and surface EEG (Fig. 1).

As previously demonstrated (Bouilleret et al., 1999; Riban et al., 2002; Arabadzisz et al., 2005; Gröticke et al., 2008), 4 weeks after the unilateral kainate injection a localized hippocampal sclerosis is present in the injected dorsal hippocampus, characterized by a

\footnotetext{
$\leftarrow$

(Figure legend continued.) on the injected hippocampus signal, while at the same time no spikes are observed on the noninjected hippocampus signal. Bottom, Expanded views for both electrodes at the onset of the paroxysmal discharges ( $5 \mathrm{~s}$ window, corresponding to the green rectangles on the traces); raw signal is presented above, the FRs range below. Green represents the first epileptic spikes over the injected hippocampus. Note the lack of ictal discharges (and a preserved theta-rhythm) over the noninjected hippocampus. Calibration: $0.1 \mathrm{mV}$. B, Intracerebral recording showing an example of a HPD that lasted 41 s in the injected hippocampus. Green line indicates onset. Discharges show clear phase inversions at the level of the molecular layer of the dentate gyrus (MoDG) in the injected hippocampus. No ictal discharges are seen in the opposite hippocampus recorded simultaneously. C, Illustrative example of a HPD recorded in the injected hippocampus that lasted $36 \mathrm{~s}$. Blue rectangle represents the period of postictal suppression that follows. Time and voltage scale bars as in $\boldsymbol{B}$. $\boldsymbol{D}$, Example of a HPD recorded 4 weeks after kainate injection simultaneously at the surface and within both hippocampi with combined EEG-iEEG that lasted $44 \mathrm{~s}$. Traces are filtered with a low pass at $30 \mathrm{~Hz}$, to highlight the positive spikes on surface traces (bold segments). These surface epileptic discharges are synchronized with an intra-LH epileptic dipole at the level of the MoDG. No epileptic activity can be observed in the contralateral noninjected hippocampus. Pyr, Pyramidal layer; MoDG, molecular layer of the dentate gyrus; PoDG, polymorph layer of the dentate gyrus.
} Methods.
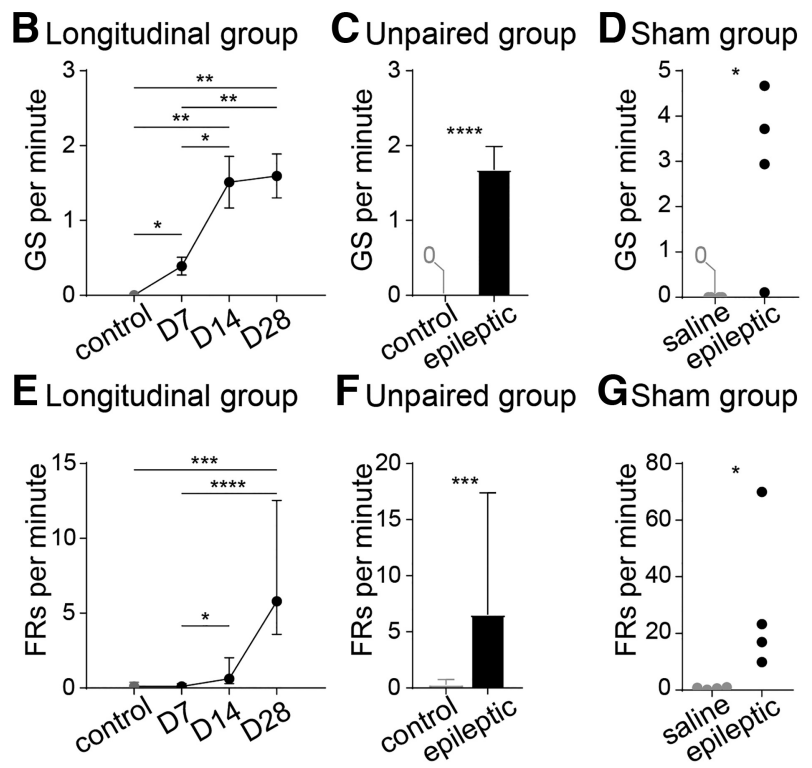

Figure 5. Epileptic phenotype of the kainate mouse model of TLE. $A, 0$ Occurrence per minute of HPDs reminiscent of epileptic in control animals $(n=23), 7 \mathrm{~d}$ after kainate injection $(n=12), 14 \mathrm{~d}$ after kainate injection $(n=12)$, and $28 \mathrm{~d}$ afte ( The increase is significant across the disease (control: median $=0,25-75$ percentile $=0-0,07: 0$

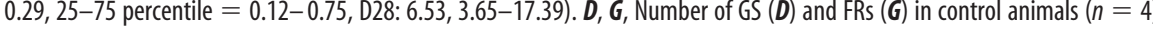
D28: 20.11, 11.65-58.28). ${ }^{*} p<0.05,{ }^{* *} p<0.01,{ }^{* * *} p<0.001,{ }^{* * * *} p<0.0001$. For the statistical tests used, see Materials and

decrease in CA1 and CA3 pyramidal cells and a marked dispersion of dentate gyrus granule cells. In contrast, no structural alteration is observed in the contralateral hippocampus (for an illustrative example, see Fig. 2). To further confirm the localization of the effect of the initial insult, large-scale histopathological analyses were performed during the latent phase after kainate injection (at D2 and D7; Fig. 3) using Fluoro-jade staining, which is a marker of neuronal cell death. As expected, we observed a gradual degeneration of the dorsal $\mathrm{LH}$ with marked neuronal death in CA1, CA2, and dentate gyrus after injection of kainate ( $n=6$ at D2 and $n=6$ at D7) but not saline ( $n=4$ at D2 and $n=$ 4 at D7). Fluoro-jade staining was not detected in the contralateral hippocampus, except to a moderate extent in the dorsal CA1 region of 1 animal at D2. A few Fluoro-jade-positive cells could also be observed in several animals in the ventrolateral region of the ipsilateral hippocampal formation (i.e., in the entorhinal cortex) but never in the neocortex. No Fluoro-jade-positive cells were found in the frontal cortex in which pathological FRs were detected (see below).

HPDs that were reminiscent of focal seizures appeared as periods of focal ictal epileptic discharges in the surface EEG with superimposed FR lasting from a minimum of $5 \mathrm{~s}$ to minutes. Figure 4 shows the activity recorded at D28 at surface EEG electrodes located over the injected (Fig. 4A-C) and noninjected (Fig. $4 D-F$ ) hippocampus during a representative HPD. Ictal activity was characterized by sustained sharp rhythmical spiking that remains restricted to the injected hippocampus and by an increase 


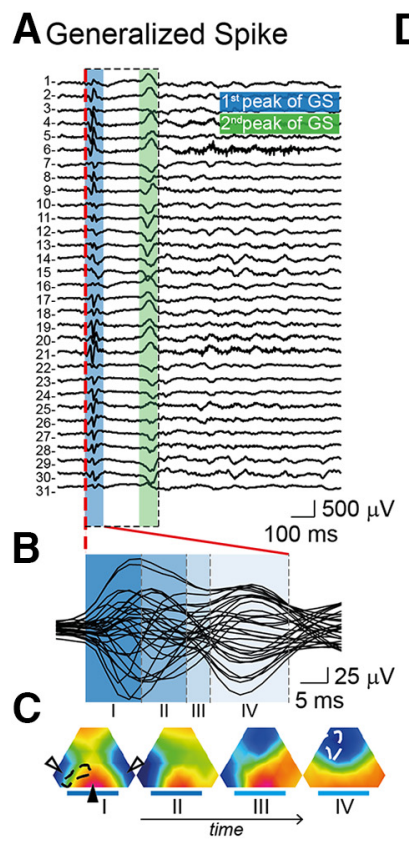

D Combined EEG-iEEG

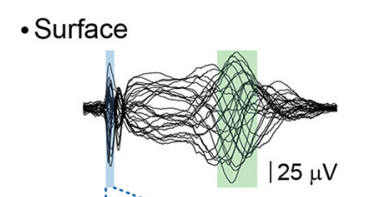

Current-source density
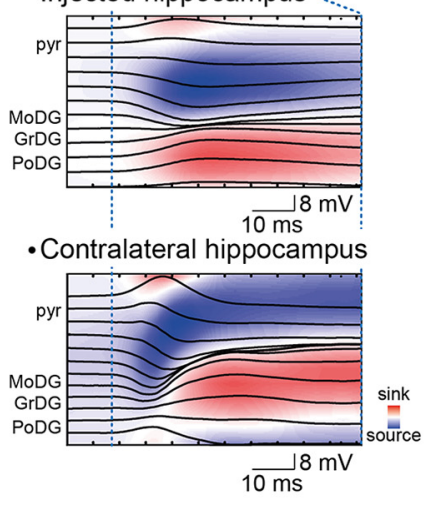

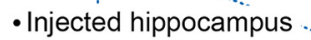

\section{E GS onset}
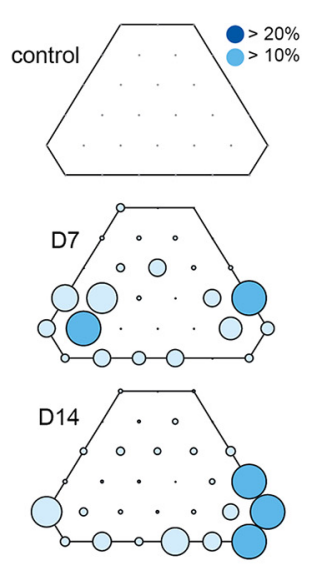

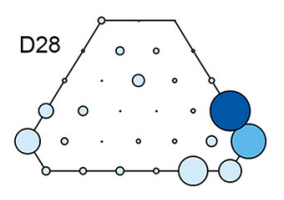

Figure 6. Development of GS as indicator of the epileptic network. A, Representative GSs (EEG, raw local field potential [LFP]). Two peaks are separated by a period of low-amplitude activity. Red line indicates $G S$ onset. For electrode locations, see Figure $1 B$. B, Superimposed average traces of the first peak of GS (663 GS, 21 animals at D28). C, The spatiotemporal propagation pattern of GS is highly stable and characterized by a sequence of 4 consecutive stable topographies (for cluster analysis, see Materials and Methods). Normalized voltage values are color-coded from negative blue to positive red values. White and black arrowheads indicate position of the focal negative and positive maxima of the hippocampal dipoles, respectively. Black dashed line indicates position of the injected hippocampus. White dashed line indicates position of the left primary motor cortex. D, Combined EEG-iEEG. Top, Representative average GS $(n=30)$ in 1 animal, with blue and green squares indicating the first and second peaks, respectively. Bottom, Average current-source density in the LH and RH during the first peak of GS showing a bihippocampal activation at GS onset. Current-source density traces are superimposed on color-coded plots of the interpolated currentsource density values. Sink sources are organized similarly in LH and RH with notable differences in the kinetics of the slopes. $\boldsymbol{E}$, Localization of GS onsets as the disease progresses (surface EEG, $n=12$ animals at each time points). The larger the dot, the higher the proportion of GS showing a statistical onset at the electrode. Above $10 \%$ and $20 \%$, the color changes with the proportion of onset.

power in the theta-alpha range as well as in the high-frequency oscillations range. Although animals were not recorded chronically, we identified a total of 70 HPDs in surface EEG in 21 animals at D28 during the acute EEG recording sessions (Fig. 5A; median duration $=13.5 \mathrm{~s}$, interquartile 9.2-20.7; frequency of occurrence ranging from 0 to 0.8 per minute, median of 0.05 per minute). All detected HPDs were restricted to electrodes in the region of the injected hippocampus (electrodes 16, 17, 18, 19, 24; Fig. 1). Among all animals at D28, 3 HPDs secondarily generalized from the injected hippocampus to the contralateral hippocampus and then to neocortical areas. These events are reminiscent to secondarily generalized seizures and were associated with clonic paw and face movements, as described previously (Riban et al., 2002). Only 1 HPD was recorded at D14 from 12 animals. No HPD was observed in animals before kainate injection (D-1 controls, $n=23)$ or $7 \mathrm{~d}$ afterward $(n=12)$. No HPD was detected at D28 in saline-injected animals $(n=4)$. During iEEG recordings in both hippocampi and frontal cortex during the fourth week (Fig. 1C; see Fig. 9), HPDs were similarly all restricted to the kainate-injected hippocampus (median of 0.1 HPD per minute) and were not detected in saline-injected animals $(n=8$ kainate-injected animals; $n=4$ saline-injected animals; one iEEG recording session of 50 min per animal). Combined EEG-iEEG recordings taken 4 weeks after the kainate injection in 6 animals confirmed that surface ictal activities are restricted to surface electrodes over the injected hippocampus and correspond to ictal activities recorded in the sclerotic hippocampus (i.e., the EF) (Fig. 4G). Thus, in agreement with previous reports, intrahippocampal kainate injection leads to a focal disease as defined by localized lesions and HPDs expression.

\section{Identification of epileptic spikes propagating within a preferential large- scale epileptic network}

Although histopathological analysis and seizure recordings pointed toward a focal disease, multichannel EEG recordings revealed the presence of numerous GSs at 4 weeks. GSs are a type of IED previously unreported in this mouse model and characterized by a complex spike-andwave pattern that does not remain focal but invades all surface electrodes (Fig. $6 A$ ). A total of 663 GSs were recorded at D28 across 21 animals with a mean frequency of 1.59 per minute (Fig. $5 C$ ). These GSs were highly similar across mice in terms of duration (mean \pm SEM: $250 \pm$ $10 \mathrm{~ms}$ ) and waveform: they started with a 30-40 ms period of high-amplitude peak followed by a flattening of the EEG and then a second period of high amplitude peak. All 21 animals recorded at D28 expressed GS, but GSs were never detected either before kainate injection (D-1 controls, $n=23$, Fig. $5 C$ ) or in saline-injected animals (sham group, $n=4$, Fig. $5 D$ ). We then made paired analyses using recordings from the longitudinal group of mice that were studied at all time points (D-1 control, D7, D14, and D28; $n=12$ animals). The output of this analysis showed that, although no GSs were present before the injection, GSs were present at D7 ( 0.3 per minute) and then gradually and significantly increased along the course of the disease up to an average of 1.5 per minute at D28 (Fig. 5B). Thus, whereas seizure-like events were almost absent at D7 and D14 after kainate injection, GSs progressively emerged in the early phase.

GSs did not appear simultaneously at all electrodes but rapidly propagated across surface electrodes (Fig. 6A). To describe the spatiotemporal propagation of GS across the brain, we performed a topographical analysis of the EEG signal during the first high amplitude peak (Fig. 6B) using clustering and back-fitting algorithms of the potential maps (Lantz et al., 2003; Michel et al., 2004; Mégevand et al., 2008). As shown in Figure 6C, the pattern of propagation of GSs was best described by a sequence of 4 successive potential maps of surface brain activity (topographical analysis of the grand-average GS at D28), suggesting that the hippocampi and then the frontal regions sequentially became predominant nodes of the epileptic network. The topography of the first voltage map displays lateral negative poles and a medial positive pole that flanked the positions of the 2 hippocampal axes. Given the circular orientation of the hippocampal cells, this topography suggested that concomitant sources were present across both hippocampi and generated the observed extended dipoles. To prove the actual presence of active generators in the dorsal hippocampus, we then proceeded to examine combined EEG- 
iEEG in 6 kainate-injected animals at D28. These recordings confirmed the presence of active generators in both hippocampi during the initial map (see below; and Fig. 6D). Subsequently, frontal regions exhibited a strong focal activity indicating a frontal propagation (Fig. 6C, maps III and IV). Back-fitting these maps to the GSs of individual animals using topographical correlations showed that their chronology was conserved in all animals, confirming their consistency. Thus, GS propagated within a preferential large-scale network with stable predominant nodes that encompassed the lesioned hippocampus (i.e., the EF), the contralateral, nonlesioned hippocampus as well as the frontal cortical regions bilaterally.

\section{Progressive shift in onset of GSs}

The concomitant sources in the lesioned and nonlesioned hippocampi during the first map of the GS raised the question of where these interictal events started (i.e., in the EF or elsewhere in the EN). Combined EEG-iEEG 4 weeks after kainate injection confirmed the presence of generators in both hippocampi at GS onset (Fig. 6D), in line with the bihippocampal initial source on surface EEG. The currentsource density graphs, however, were quite different in the lesioned and nonlesioned hippocampi, with slower kinetics in the sclerotic hippocampus, which occurred presumably due to the major morphological alterations that followed kainate injection (Bouilleret et al., 1999; Arabadzisz et al., 2005). To study the localization of GS onsets across animals and across time, we quantified the number of GS onsets across surface EEG electrodes (see Materials and Methods) in the longitudinal group of animals (Fig. 6E). Although the majority of GSs had an onset at electrodes above the kainate-injected hippocampus at D7, in recordings after D7 the onset was identified more often in the contralateral hemisphere, in particular at electrodes located over the contralateral hippocampus. Consequently, the left/right ratio of GS onsets calculated in each mouse decreased significantly with disease progression (ratio of GSs starting at electrodes above the injected hippocampus, e17-e21, divided by those starting at electrodes above the noninjected hippocampus, e2-e6, D7: median 3, interquartile range 2-5.2, D14: $0.66,0.13-$ 0.85, D28: 0.41, 0.16-1.33, Kruskal-Wallis + post hoc, $p<0.05$ from D7 to D14 and from D7 to D28). This topographical shift in GS onset suggests that, as the disease evolved, epileptic activities could be generated not only in the focus but at the network level as well.

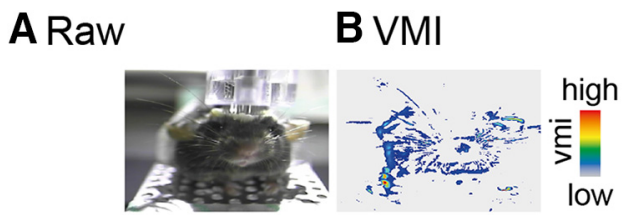

\section{Motor activity associated with GS}
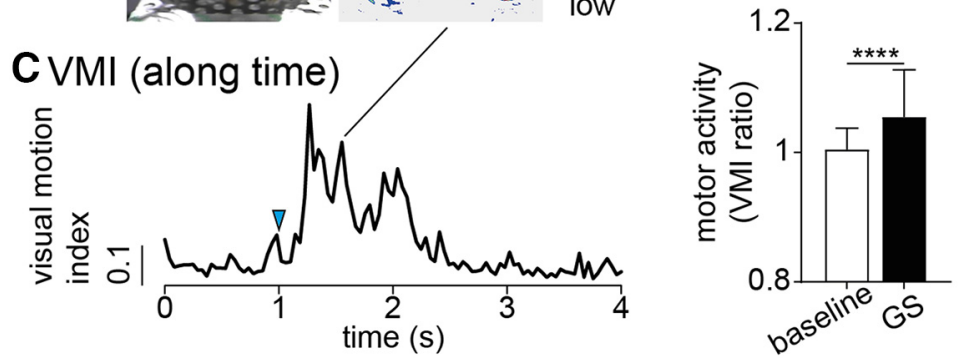

Figure 7. GSs are associated with increased motor activity. $\boldsymbol{A}$, One frame from a video recorded during a surface EEG session. $\boldsymbol{B}$, The difference of pixel luminosity from one frame to another provides a quantitative unit to estimate movements: the warmer colored regions represent where the animal has moved more (for a detailed description of the process, see Materials and Methods). C, VMI along time, calculated by averaging luminosity differences of all pixels at each time point around one GS. Blue arrowhead indicates the onset of the GS. The motor reaction goes beyond the duration of GS.D, VMI ratios are calculated by dividing the period during and after GS ( -20 to $800 \mathrm{~ms}$ ) by the period before GS, and compared with VMI ratios calculated around random markers in the EEG (baseline, see Materials and Methods). The difference was significant, revealing an evoked motor response (median, 25-75 percentile, week $4, n=15$ animals, ${ }^{* * * *} p<0.0001$, Wilcoxon test).

\section{A Surface EEG: typical FR \\ B Surface EEG: electrodes color code}

| $50 \mu \mathrm{V}$ (raw LFP)

$10 \mu \mathrm{V}(200-550 \mathrm{~Hz})$

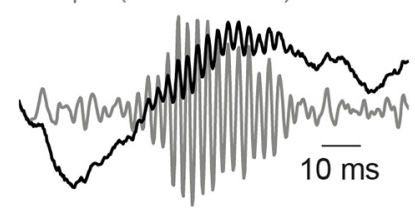

\section{Surface EEG: parameters of FRs along the disease}
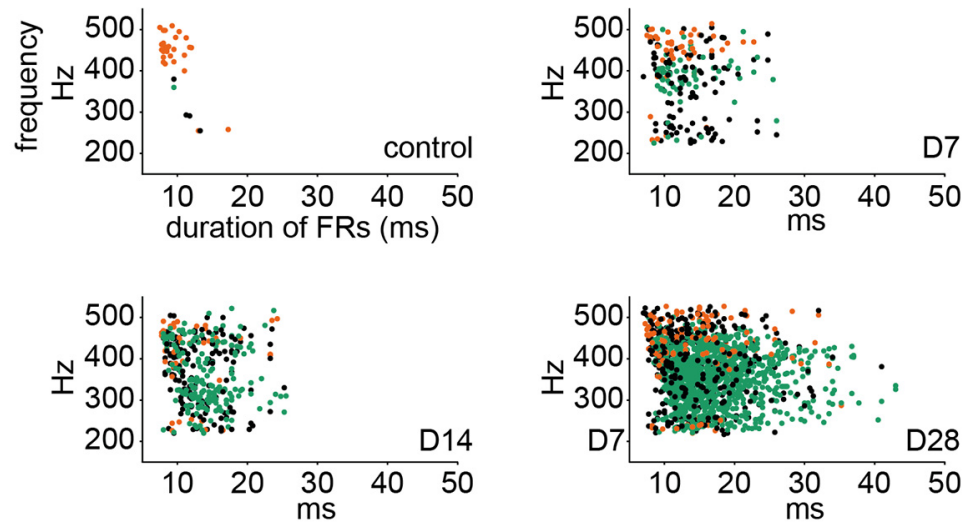

Figure 8. FRs increase as the disease progresses in the EF and in the epileptic network. $A$, Example of an FR recorded with surface EEG. Black represents raw LFP. Gray represents filtered $200-550 \mathrm{~Hz}$. B, Color code for C. C, Distribution of FRs in the longitudinal group recorded over the somatosensory cortex (orange), the injected hippocampus (green), and all other contacts (black), as a function of their duration and intrinsic frequency in control and as the disease progresses.

\section{Propagation of GSs causes myoclonic jerks}

A raw visual inspection of video monitoring revealed frequent jerky movements during GS, ranging from discrete whisker motions, to face, paw, and body shivers. To quantify these motor symptoms, we measured the VMI around GS and during baseline 
A Injected hippocampus fast-ripple: combined EEG-iEEG

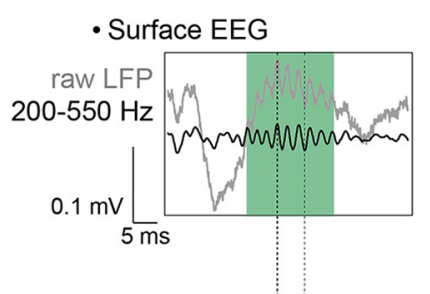

- iEEG (injected hippocampus)
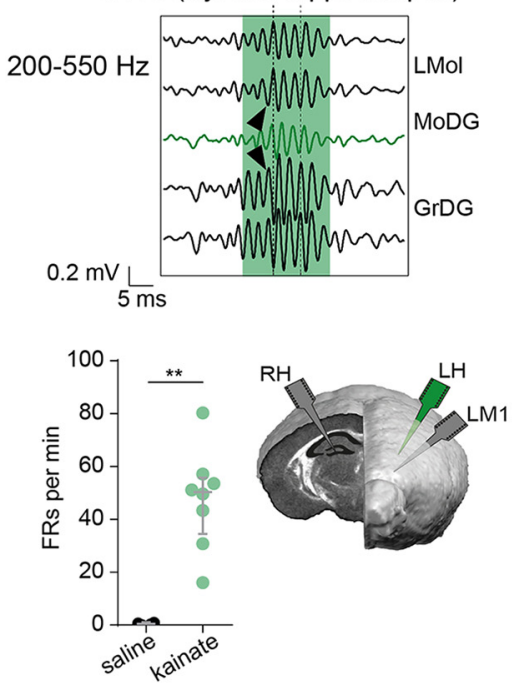

B Frontal cortex fast-ripple: intracortical recording
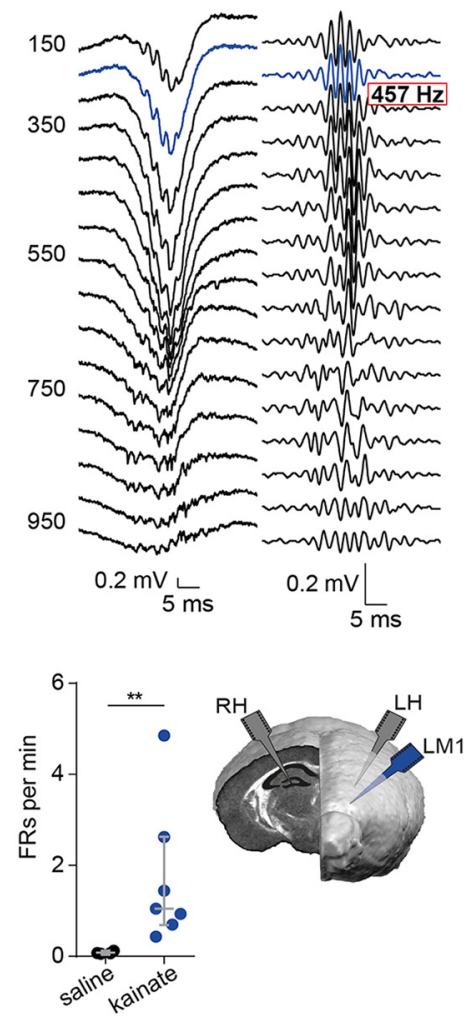

Figure 9. Epileptic FRs are generated in the EF as well as in the epileptic network. A, Example of an FR recorded in the injected hippocampus during a combined EEG-iEEG recording session. Top, Surface electrode located over the injected hippocampus. Gray represents raw LFP. Black represents filtered $200-550 \mathrm{~Hz}$. Bottom, Signals recorded simultaneously in the injected hippocampus with five selected electrode traces located around the intrahippocampal generator of the FR. Note the inversion of potentials (black arrowheads), which indicates that the generator is at the level of the molecular layer of the dentate gyrus (MoDG). Note also the lack of phase lag (see the black dotted bars on the peak and trough of the FR) between the surface- and depth-recorded FR, which indicates that surface and depth electrodes record the same event. LMol, Lacunosum molecular layer; GrDG, granulosum layer of the dentate gyrus. Bottom, Histogram of FRs recorded with intracortical electrodes in the injected hippocampus. FRs per minute are significantly higher in the injected hippocampus of kainite-injected animals than in saline-injected animals (median, 25-75 percentile: saline: $0.46,0.09-0.81$, kainate: $50.35,33.92-56.25$, Mann-Whitney test: ${ }^{* *} p=0.004,8$ kainate +4 saline mice with intracerebral EEG, D28). B, Example of a left primary motor cortex FR recorded with intracortical EEG (left: raw LFP, right: filtered, $200-550 \mathrm{~Hz}$ ), which is most clearly seen in the middle layers II/III (blue). Bottom, Histogram of FRs recorded with intracortical electrodes in the left motor cortex. FRs per minute are significantly higher in the frontal cortex of kainate-injected than in saline-injected mice $28 \mathrm{~d}$ after injection (saline: $0.07,25-75$ percentile: $0.06-0.11$, kainate: $1.05,0.7-2.62$, Mann-Whitney test: ${ }^{* *} p=0.0061,7$ kainate +4 saline mice with intracerebral EEG, D28; same animals as in A). Because of technical issues, only 7 recordings from the frontal cortex could be included.

EEG in 15 mice at D28 after kainate injection (see Materials and Methods; Fig. 7). This analysis revealed that GS induced a significant increase in motor activity, demonstrating that an intense semiology was associated with GS propagation. This finding is particularly interesting in the light of the propagation pattern of GS toward frontal areas and may suggest that the frontal cortex recruitment during GS activates frontal motor areas.

Together, these results show that GSs are symptomatic activities propagating in a stable large-scale EN in which the EF is the main hub. However, the onset of GSs was not systematically identified at LH-specific electrodes, which suggests that GSs could also be initiated in the EN (see below).

Focal and remote epileptic FRs emerge in extended regions after induction of epilepsy, and increase as the disease evolves Controversy exists regarding the meaning of FRs even though they are generally considered to be markers of epileptogenicity
(Jacobs et al., 2010; Jefferys et al., 2012; Staba, 2012; Zijlmans et al., 2012; Menendez de la Prida et al., 2015). Before the induction of the disease, as illustrated in Figure 8, FRs were rare and restricted to barrel field regions in which they represent a physiological population of FRs (Baker et al., 2003). A widespread expression of FRs then emerged throughout the course of the disease: across all electrodes, FRs increased from $0.1 / \mathrm{min}$ in control recordings before kainate injection up to a median of 6 FRs/min 4 weeks after in the longitudinal paired and in the unpaired recordings (Figs. $5 E, F, 8$ ). An additional surface EEG experiment revealed that the number of FRs at 4 weeks was also significantly higher compared with salineinjected mice ( $p=0.0286, n=4$ in each group 4 weeks after injection, Mann-Whitney test; Fig. $5 G$ ). Although FRs increased tremendously above the $\mathrm{EF}$ ( $80 \%$ of all FRs recorded with surface EEG were detected above the $\mathrm{EF}$ ), they also increased outside the EF, such as at RH and at frontal electrodes, whereas FRs were almost absent in the controls (from 0 to $0.07 / \mathrm{min} \pm 0.02 / \mathrm{min}$ SEM, $p=0.0028$ calculated at the 2 most rostral electrodes rows, Friedman test along the 4 weeks).

Intracortical electrodes are more accurate for detecting FRs, because they are closer to neuronal generators. iEEG confirmed the generation of abundant FRs in the $\mathrm{LH}, \mathrm{RH}$, and frontal cortex of kainateinjected animals, whereas they were almost absent in saline-injected animals (Fig. 9; kainate-injected animals: $n=8$ in the LH and $n=7$ in the FC, salineinjected animals: $n=4$ in both regions, Group 3 in Table 1).

The observation of a significant increase of FRs in the EF and the presence of remote FRs in epileptic mice but not in controls indicated their pathological nature. Furthermore, physiological FRs at D-1 and FRs recorded after kainate injection had different intrinsic characteristics as early as at D7, with lower intrinsic frequency and longer duration compared with controls, as previously reported (Matsumoto et al., 2013) (Fig. 8C; duration, control: median $=9 \mathrm{~ms}$, interquartile $8.3-10.3 \mathrm{~ms}$, D7: $12.3 \mathrm{~ms}, 9.8-15.1 \mathrm{~ms}, \mathrm{D} 14: 12.8 \mathrm{~ms}$, 10.3-15.8 ms, D28: 14.8 ms, $11.8-19$ ms, Kruskal-Wallis test: $p<$ 0.0001 ; intrinsic frequency, control: median $=441 \mathrm{~Hz}$, interquartile $416-458 \mathrm{~Hz}, \mathrm{D} 7: 400 \mathrm{~Hz}, 348-449 \mathrm{~Hz}, \mathrm{D} 14: 371 \mathrm{~Hz}, 309-431 \mathrm{~Hz}$, D28: $374 \mathrm{~Hz}, 318-420 \mathrm{~Hz}$, Kruskal-Wallis test: both at $p<0.0001$ ). We concluded that remote FRs in epileptic animals consisted of a mixture of physiological FRs, mainly above the barrel cortex, and pathological activities.

\section{Relationship between GSs, FRs, and HPDs}

In surface EEGs, we observed that FRs recorded in the region of the lesioned hippocampus (i.e., the $\mathrm{EF}$ ) or in remote regions were either generated during the GS ( $12 \%$ of the FRs in the region of 
the injected hippocampus vs $51 \%$ of the FRs in remote regions), or during background activity. Similarly, in multisite iEEG, we observed that a proportion (33\%) of FRs detected in the nonlesioned hippocampus or in the frontal cortex occurred without concomitant activity in the lesioned hippocampus, suggesting that regions other than the focus developed the capability to spontaneously generate pathological FRs.

However, the total duration of GSs was far shorter than the total duration of EEG background, indicating that the expression of FRs was concentrated during GSs. Remarkably, as seen in Figure 10, FRs occurring during GSs were strictly timelocked to the peaks of GS. This result indicated that GS could be a triggering factor that enhanced excitability enough to trigger FRs in the target nodes where GSs propagate (given that FRs identified during GSs started after the GSs, the inverse is less probable). In line with this result, the electrodes at which GSs elicited the strongest activity correlated to those that recorded the highest occurrence of FRs (Fig. $10 C)$. Moreover, the amplitude of GSs was significantly higher when an FR (and even higher with a frontal FR) was evoked than when no FR was detected (Fig. 10D). This indicated that GSs with high amplitudes had a higher propensity to elicit FRs in target regions.

Focal and remote FRs as well as GSs were already present at D7, even if their occurrence significantly increased from the latent to the chronic phase of the disease. Our acute longitudinal recordings confirmed previous findings in this model (Riban et al., 2002; Arabadzisz et al., 2005; Heinrich et al., 2006; Ledergerber et al., 2006; Rattka et al., 2013): HPD (i.e., events reminiscent of seizures) were not present at D7, rare at D14, and frequent at D28 (Fig. 5A). Acute recordings, however, did not allow to capture the exact onset of HPDs during the evolution of the disease and prevented analysis of correlations in the development of seizures and GSs or FRs. Nevertheless, the number of HPDs in the chronic stage was linked to the number of interictal epileptic activities in the large-scale EN. Indeed, the number of HPDs at D28 was significantly correlated with the number of remote FRs $\left(r^{2}=0.4229, p=0.0035\right.$, Spearman correlation, $n=21)$ and GS $\left(r^{2}=0.3929, p=0.0024\right.$, Spearman correlation, $n=21$ ), suggesting that network-wise and focal epileptic activities might represent two facets of the same disease.

\section{Do GSs and remote FRs disappear if the hippocampal focus is silenced?}

The spontaneous expression of pathological FRs outside of the EF, as well as the fact that GS onset can be detected in regions outside of the EF suggest that in the chronic stage of the disease, the EF might not be necessary to trigger remote, pathological activities specific to the epileptic condition.

\section{A Surface EEG: raw LFP}

Figure 10. FRs are associated with the propagation of GSs or can be generated spontaneously in the EF and in the epileptic

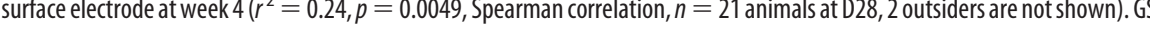
GS with at least one F-FR ("F-FR"). Global field power of GS with F-FR was significantly higher than all other GS (F-FR vs FR, no F-FR: ${ }^{* *} p<0.001$, FR, no F-FR vs no FR: ${ }^{* * *} p<0.0001$, Kruskal-Wallis test + post hoc).

We investigated this hypothesis by injecting TTX in the LH to acutely silence the EF. A group of 6 mice was recorded daily for 50 min with surface EEG from D27 to D29 after kainate injection. TTX, which is a potent inhibitor of neuronal firing (Fig. 11 $A, B$ ), was injected before the last recording session. TTX successfully silenced the EF, eliminating focal spikes (for an example of a focal epileptic spike, see Fig. 11C) and focal seizures (Fig. 12A, "injected hippocampus"). However, remote FRs and GSs continued to be expressed (Fig. 12A "network"). During TTX silencing, FRs occurred mainly in the contralateral hippocampus and frontal electrodes but not in the silenced EF (Fig. 12B). GSs recorded during LH silencing were still characterized by the typical double peak flanking decreased EEG activity of $\sim 200$ ms. Topographical analysis of GS revealed the absence of a generator over the LH region (Fig. 12D) e19, e20, and e24 showed a significant decrease of activity ( $p<0.05$, see Materials and Methods), which correlates with successful focus silencing. Interestingly, transient motor symptoms could still be detected simultaneously with GSs despite the pharmacological silencing of the primary EF (Fig. 12C).

During the early stage however (i.e., at the end of the first week after injection), TTX injection led to a significant decrease in GS expression (Fig. 12E), which indicates that the epileptic network 


\section{A Intracortical: LFP activity during TTX silencing}
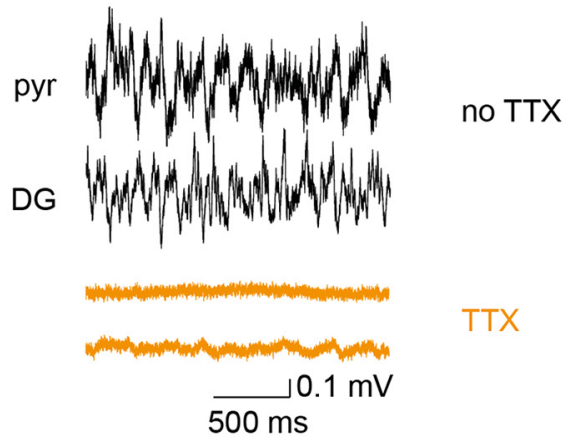

\section{B Multi-units activity}
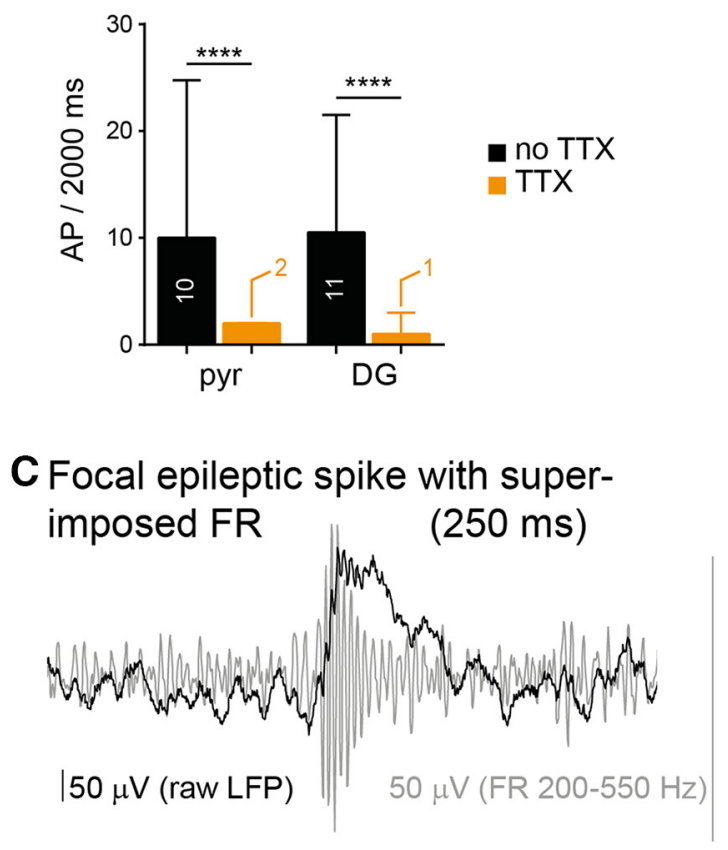

Figure 11. Silencing of the left hippocampus activity by TTX. $A$, The $2 s$ windows recordings in the pyramidal layer (top) and dentate gyrus (bottom) of the hippocampus before (black) and during silencing (orange). $\boldsymbol{B}$, Neuronal firing per minute before (black) and during (orange) TTX silencing in the injected hippocampus of 1 representative animal. The decrease during TTX silencing is significant for both the pyramidal layer (pyr, before: median $=10,25-75$ percentile $=2-25$, during TTX: 2, 1-2) and dentate gyrus (DG, before: median $=11,25-75$ percentile $=1,1-3) .{ }^{* * *} p<0.0001$. C, Example of a typical focal epileptic spike recorded with surface EEG showing a positive wave in the raw LFP (in black at the center of the $250 \mathrm{~ms}$ window) with the superimposed FR (filtered at $200-550 \mathrm{~Hz}$, in gray).

depends on the presence of the EF at the early stages of the disease. No analysis could be performed on the expression of remote FRs because they were too rare at this early stage, which we propose is a supplementary evidence for the immaturity of the EN.

\section{Discussion}

There is a considerable difference between a strictly focal epileptic syndrome and one with large-scale damages, in which extrafocal alterations cannot be neglected or ignored. The reliance of these large-scale activities on the EF is of major importance, as it defines whether the EF, the extrafocal activities, or both should be therapeutic targets. Investigating epileptic network formation is a major challenge in epilepsy research (Spencer, 2002; Bell et al., 2011; Richardson, 2012; Terry et al., 2012; Goodfellow et al., 2016). The demonstration of the existence of pathological activities independent from the EF, and their electrophysiological signature, are therefore decisive. In our work, the gradual increase of remote FRs and interictal, yet symptomatic, GSs throughout the disease progression, and the finding that they become independent from the activity of the focus, is a striking finding that contributes to the revision of the concept of focal epilepsy. Responsive neuromodulation protocols, which rely on the identification of specific electrophysiological patterns, would deeply benefit from the identification of such electrophysiological signatures of extended epileptic networks. In humans, obtaining direct proof of epileptic network development using longitudinal recordings even before the onset of seizures is challenging, if not impossible. Moreover, conflicting evidence exists on the progressive nature of epilepsy (Bartolomei et al., 2008) and translational research in animal models allows clarification of these processes in a well-controlled manner.

\section{Development of large-scale activities specific to the epileptic condition following focal epilepsy}

While certain ictal features of the kainate mouse model may differ from ictal activity in humans, suggesting that different mechanisms might underlie the generation of seizures, the intrahippocampal kainate model is appropriate to study focal epilepsies, such as mesial TLE. The identification of ictal and interictal activities is an important question in rodent models of epilepsy. Spontaneous spike-wave discharges have been described in several rodent models that may represent forms of electrographic activity other than seizures and that can be a potential confound in the detection of epileptic events (Letts et al., 2014; Pearce et al., 2014; Rodgers et al., 2015). In the well-described mouse intrahippocampal kainate model, however, several studies demonstrated that the HPDs are specific to the kainate-injected hippocampus and do not develop in saline-injected mice (Bouilleret et al., 1999; Riban et al., 2002; Arabadzisz et al., 2005; Gröticke et al., 2008; Twele et al., 2017). In agreement with that, the HPDs as well as the GSs and the drastic increase in FRs we detected are specific to kainate-injected animals and are not observed in animals before the kainate injection or after saline injection. Evidence exists that the ictogenicity of kainate might be consecutive, at least in part, to the activation of high-affinity kainate receptors of mossy fibers synapses; this enrichment of high-affinity kainate receptor in this particular region is shared between different animal species and humans (Ben-Ari and Cossart, 2000). A latent period before refractory seizures and reactive gliosis are typical features of the kainate mouse model of TLE (Riban et al., 2002) and are also major components of human TLE (Tatum, 2012; Blumcke et al., 2013), although the existence of a trigger in human TLE remains a matter of debate. Most importantly, the present model allows to study the effect of a focal disease; intraperitoneal injection of kainate leads to diffuse histopathological lesions (Scholl et al., 2013), but intrahippocampal injection leads to localized sclerotic lesions and focal seizure emergence in the injected hippocampus, sparing the contralateral hippocampus (Bouilleret et al., 2000a, b; Riban et al., 2002; Arabadzisz et al., 2005; Kralic et al., 2005; Heinrich et al., 2006; Deprez et al., 2011; Zattoni et al., 2011; Rattka et al., 2013).

Combining longitudinal large-scale surface and intracerebral recordings from the induction to the chronic stage of the disease, we here further describe the focal nature of the kainate mouse model and at the same time we provide direct evidence for the 
development of pathological activities remote from the EF (i.e., FRs and GSs). These activities are not seen before the kainate injection or in saline-injected animals and are thus specific to the epileptic condition. Although we might not have recorded exhaustively from all the potential nodes recruited during the propagation of GSs, the highly conserved pattern of propagation indicates that a preferential network supports their dynamics.

It might appear surprising that these striking electrophysiological features of GSs were never reported before in this mouse model, but this is most probably due to the lack of large-scale EEG studies in animals, which reinforces the need to use such methods in the field of epilepsy. However, generalized discharges have been described in humans (Aarts et al., 1984; Mohamed et al., 2001; Moseley et al., 2012; Pittau et al., 2013). In human TLE, these GSs were related with transient cognitive impairments and their presence before surgery associated with a bad prognosis (Aarts et al., 1984; Moseley et al., 2012). Associated to their frontal recruitment, GSs evoke significant motor responses (Fig. 7). In this mouse model of TLE, these motor symptoms are relevant because they indicate large-scale consequences of a focal disease, and they match with the frontal propagation of GSs. Given the high rate of GSs in the chronic stage of the disease (up to $1.5 / \mathrm{min}$ ), these large-scale pathological spikes represent highly debilitating activities. Although memory deficits are typical impairments seen in TLE patients, it is important to note that network-wise, other domains are affected by the epileptic condition (Oyegbile et al., 2004; Bell et al., 2011; Savage, 2014), including motor functions (Oyegbile et al., 2004). Myoclonic jerks are not typical signs of TLE, but we argue that transient cognitive deficits in humans could be generated similarly through the propagation of epileptic activity in large-scale epileptic networks (Aldenkamp and Arends, 2004).

\section{Are pathological FRs truly restricted to the EF?}

Previous studies considered FRs as specific to the EF (Jacobs et al., 2008, 2010; Menendez de la Prida et al., 2015). In humans, there is still debate regarding how to distinguish physiological FRs from pathological FRs (von Ellenrieder et al., 2016). In this study, using longitudinal recordings starting before the induction of the disease, we showed that FRs linked to the disease emerge outside of the primary EF (Figs. 8, 9). Because we observed a progressive increase of FRs along the disease, and given that FRs have been shown to be related to epileptic activity (Foffani et al., 2007; Jacobs et al., 2010), this increase in extrafocal regions might indicate an exacerbation of the disease on the large scale.

At advanced stages of the disease, remote FRs cannot be suppressed by pharmacological silencing of the EF, which indicates that self-sustaining pathological remote activities are established. Because FRs, or rather their changes, can be detected by

\section{B Quantitative localization of FRs}

$0<0.1 / \mathrm{min}$

$0.1-0.2 / \mathrm{min}$

$>0.2 / \mathrm{min}$

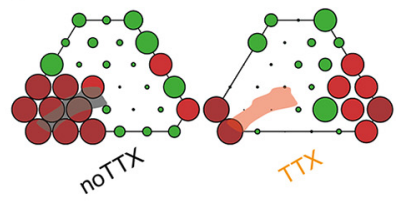

ESilencing at D7

D GS topography under TTX silencing

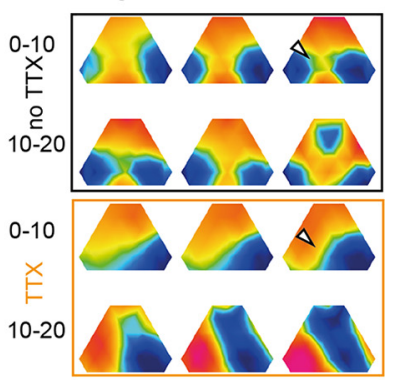

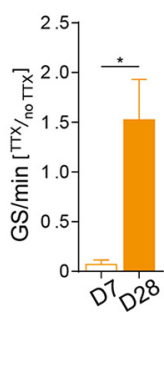

Figure 12. The epileptic network becomes independent of the epileptic focus at week 4. A, Occurrence of focal spikes, HPDs reminiscent of seizures, remote FRs and GSs in mice without TTX (black, 2 control-epileptic recording sessions at D27 and D28) and IT TTX silencing of the injected hippocampus (orange, 1 recording session at D29) in the same 6 epileptic animals. FRs of the silencing There is a considerable decrease of FRs of the injected hippocampus durion silencing bute (left) and during (right) TIX Jirst $20 \mathrm{~ms}$ of GSs recorded during TTX silencing showing that, as expected, the injected hippocampus dipole is at D7 versus D28 after kainate injection. At D7, TTX silencing was able to decrease GS occurrence, but not at D28 (mean \pm SEM, difference of ratio: Mann-Whitney test, ${ }^{*} p=0.0238$ ).

high-density scalp EEG in an individual patient (Lu et al., 2014; Zelmann et al., 2014), the evolution toward a chronic, late-stage disease could be monitored more closely, and timely interventions used. Our results suggest that, although FRs convey incomplete localizing information, they may be important biomarkers of the temporal evolution of the disease.

Although it was not significant, there was a tendency of FRs to increase during focus silencing. One could suggest that the substantial epileptic activities triggered by the EF might overcome the activity of other pathological nodes of the EN, a hypothesis that should be addressed in future studies. Worsening of the EN after focal resection would, however, be a devastating observation for clinicians.

\section{EF silencing is ineffective in treating the epileptic network in the late stage of the disease}

GSs and FRs are dependent on the focus in the latent phase of the disease but not in the chronic stage. Our interpretation is that those pathological activities are triggered by the EF during the latent phase, progressively altering the remote hubs of the EN that ultimately become capable of generating self-sustaining IEDs. In animal studies, proepileptic and compensatory plasticity changes have been demonstrated within the EF (Scharfman, 2002), and it has been hypothesized that ictal and interictal activities may even lead to the formation of secondary epileptic hubs outside the 
focus (Bragin et al., 2000; Khalilov et al., 2003). Both GS and FRs may prompt the formation and the consolidation of abnormal neuronal networks in remote areas using similar plasticity mechanisms. Future studies should address the causal effects of these IEDs on the development of large-scale EN and the potential effects in remote regions of the initial insult.

The ability to control the EN at D7, but not at D28, highlights the progressive nature of the disorder. To the best of our knowledge, this study is the first demonstration of a dynamical change in focal epilepsy. Identifying such critical changes in human epilepsy would undoubtedly influence the timing of interventional treatments (Fisch et al., 2016) that are essential to avoid potentially dangerous, lengthy drug trials. Very few studies exist on early surgical treatments (Engel et al., 2012) and their long-term outcomes compared with conventional studies in which the average duration of epilepsy is $\sim 18-25$ years. This paucity of research during the earliest stage of the disease might explain why, in humans, beneficial effects (Krumholz et al., 2015) as well as a lack of effects (Janszky et al., 2000; Jutila et al., 2002) on memory functions and seizure control following surgery have been shown (Téllez-Zenteno et al., 2005).

There is currently only a limited knowledge on the extrafocal pathology in the mouse model of hippocampal sclerosis, although a few studies have supported the hypothesis of remote changes associated with the activity of the epileptic focus (Langlois et al., 2010; Gelinas et al., 2016). To the best of our knowledge, there has not yet been a detailed study investigating the large-scale modifications emerging after the induction of an epileptic focus, with high temporal and spatial resolutions, and through a chronic recording design.

To investigate whether long-term changes might trigger the development of secondary foci would be of major importance and will need to be investigated in further studies. The emergence of secondary foci with repetitive and propagated ictal-like events has been shown previously in vitro (Khalilov et al., 2003). Our claim, also shared by many others (Bell et al., 2011; Richardson, 2012; Fisher et al., 2014), is that epilepsy is not only a disease of seizures; the investigation of ongoing pathological activities, not explicitly linked to ictal behavioral signs and symptoms, is mandatory to obtain a global insight of the epileptic brain.

We believe that our results represent a significant advance in the field of focal epilepsy, revealing with new tools inspired by clinical research, such as combined surface high-density EEG and intracortical recordings, the occurrence of large-scale pathological alterations. It is therefore crucial that subsequent research is aimed at identifying the mechanisms by which these alterations are generated.

In conclusion, using the kainate mouse model of hippocampal sclerosis, our results reveal that this disease is more widespread than previously thought; and although more analyses are needed on the behavioral consequences of the large-scale pathology, these remote activities specific to the epileptic condition cannot be ignored. Our results demonstrate that focal epilepsy not only involves recurrent seizures but is a network disease (Richardson, 2012) that leads to long-term changes outside the primary focus. These results call for further studies investigating the mechanisms of generation of the remote changes, and whether these remote changes could lead, over time, to the formation of extrafocal, ictal triggering zones. From a therapeutic perspective, they motivate the more precise identification of the behavioral consequences of large-scale electrophysiological dysfunctions and potential new therapeutic targets.

\section{References}

Aarts JH, Binnie CD, Smit AM, Wilkins AJ (1984) Selective cognitive impairment during focal and generalized epileptiform EEG activity. Brain 107:293-308. CrossRef Medline

Aldenkamp AP, Arends J (2004) Effects of epileptiform EEG discharges on cognitive function: is the concept of "transient cognitive impairment" still valid? Epilepsy Behav 5:S25-S34. CrossRef Medline

Arabadzisz D, Antal K, Parpan F, Emri Z, Fritschy JM (2005) Epileptogenesis and chronic seizures in a mouse model of temporal lobe epilepsy are associated with distinct EEG patterns and selective neurochemical alterations in the contralateral hippocampus. Exp Neurol 194:76-90. CrossRef Medline

Baker SN, Curio G, Lemon RN (2003) EEG oscillations at $600 \mathrm{~Hz}$ are macroscopic markers for cortical spike bursts. J Physiol 550:529-534. CrossRef Medline

Bartolomei F, Chauvel P, Wendling F (2008) Epileptogenicity of brain structures in human temporal lobe epilepsy: a quantified study from intracerebral EEG. Brain 131:1818-1830. CrossRef Medline

Bell B, Lin JJ, Seidenberg M, Hermann B (2011) The neurobiology of cognitive disorders in temporal lobe epilepsy. Nat Rev Neurol 7:154-164. CrossRef Medline

Bénar CG, Chauvière L, Bartolomei F, Wendling F (2010) Pitfalls of highpass filtering for detecting epileptic oscillations: a technical note on "false" ripples. Clin Neurophysiol 121:301-310. CrossRef Medline

Ben-Ari Y, Cossart R (2000) Kainate, a double agent that generates seizures: two decades of progress. Trends Neurosci 23:580-587. CrossRef Medline

Blumcke I, Cross JH, Spreafico R (2013) The international consensus classification for hippocampal sclerosis: an important step towards accurate prognosis. Lancet Neurol 12:844-846. CrossRef Medline

Bonilha L, Edwards JC, Kinsman SL, Morgan PS, Fridriksson J, Rorden C, Rumboldt Z, Roberts DR, Eckert MA, Halford JJ (2010) Extrahippocampal gray matter loss and hippocampal deafferentation in patients with temporal lobe epilepsy. Epilepsia 51:519-528. CrossRef Medline

Bouilleret V, Ridoux V, Depaulis A, Marescaux C, Nehlig A, Le Gal La Salle G (1999) Recurrent seizures and hippocampal sclerosis following intrahippocampal kainate injection in adult mice: electroencephalography, histopathology and synaptic reorganization similar to mesial temporal lobe epilepsy. Neuroscience 89:717-729. CrossRef Medline

Bouilleret V, Loup F, Kiener T, Marescaux C, Fritschy JM (2000a) Early loss of interneurons and delayed subunit-specific changes in GABAa-receptor expression in a mouse model of mesial temporal lobe epilepsy. Hippocampus 10:305-324. CrossRef Medline

Bouilleret V, Schwaller B, Schurmans S, Celio MR, Fritschy JM (2000b) Neurodegenerative and morphogenic changes in a mouse model of temporal lobe epilepsy do not depend on the expression of the calciumbinding proteins parvalbumin, calbindin, or calretinin. Neuroscience 97: 47-58. CrossRef Medline

Bragin A, Engel J Jr, Wilson CL, Fried I, Mathern GW (1999) Hippocampal and entorhinal cortex high-frequency oscillations $(100-500 \mathrm{~Hz})$ in human epileptic brain and in kainic acid-treated rats with chronic seizures. Epilepsia 40:127-137. CrossRef Medline

Bragin A, Wilson CL, Engel J Jr (2000) Chronic epileptogenesis requires development of a network of pathologically interconnected neuron clusters: a hypothesis. Epilepsia 41:S144-152. CrossRef Medline

Brunet D, Murray MM, Michel CM (2011) Spatiotemporal analysis of multichannel EEG: CARTOOL. Comput Intell Neurosci 2011:1-15. CrossRef Medline

Buzsáki G, Buhl DL, Harris KD, Csicsvari J, Czéh B, Morozov A (2003) Hippocampal network patterns of activity in the mouse. Neuroscience 116:201-211. CrossRef Medline

Coito A, Plomp G, Genetti M, Abela E, Wiest R, Seeck M, Michel CM, Vulliemoz S (2015) Dynamic directed interictal connectivity in left and right temporal lobe epilepsy. Epilepsia 56:207-217. CrossRef Medline

Cowansage KK, Shuman T, Dillingham BC, Chang A, Golshani P, Mayford M (2014) Direct reactivation of a coherent neocortical memory of context. Neuron 84:432-441. CrossRef Medline

Deprez F, Zattoni M, Mura ML, Frei K, Fritschy JM (2011) Adoptive transfer of T lymphocytes in immunodeficient mice influences epileptogenesis and neurodegeneration in a model of temporal lobe epilepsy. Neurobiol Dis 44:174-184. CrossRef Medline

Engel J Jr, McDermott MP, Wiebe S, Langfitt JT, Stern JM, Dewar S, Sperling MR, Gardiner I, Erba G, Fried I, Jacobs M, Vinters HV, Mintzer S, 
Kieburtz K, Kieburtz K (2012) Early surgical therapy for drug-resistant temporal lobe epilepsy: a randomized trial. JAMA 307:922-930. CrossRef Medline

Fisch L, Lascano AM, Vernaz Hegi N, Girardin F, Kapina V, Heydrich L, Rutschmann O, Sarasin F, Vargas MI, Picard F, Vulliémoz S, HéritierBarras AC, Seeck M (2016) Early specialized care after a first unprovoked epileptic seizure. J Neurol 263:2386-2394. CrossRef Medline

Fisher RS, Scharfman HE, deCurtis M (2014) How can we identify ictal and interictal abnormal activity? In: Issues in clinical epileptology: a view from the bench (Scharfman HE, Buckmaster PS, eds), pp 3-23. Dordrecht, The Netherlands: Springer.

Foffani G, Uzcategui YG, Gal B, Menendez de la Prida L (2007) Reduced spike-timing reliability correlates with the emergence of fast ripples in the rat epileptic hippocampus. Neuron 55:930-941. CrossRef Medline

Gelinas JN, Khodagholy D, Thesen T, Devinsky O, Buzsáki G (2016) Interictal epileptiform discharges induce hippocampal-cortical coupling in temporal lobe epilepsy. Nat Med 22:641-648. CrossRef Medline

Goodfellow M, Rummel C, Abela E, Richardson MP, Schindler K, Terry JR (2016) Estimation of brain network ictogenicity predicts outcome from epilepsy surgery. Sci Rep 6:29215. CrossRef Medline

Gröticke I, Hoffmann K, Löscher W (2008) Behavioral alterations in a mouse model of temporal lobe epilepsy induced by intrahippocampal injection of kainate. Exp Neurol 213:71-83. CrossRef Medline

Heinrich C, Nitta N, Flubacher A, Müller M, Fahrner A, Kirsch M, Freiman T, Suzuki F, Depaulis A, Frotscher M, Haas CA (2006) Reelin deficiency and displacement of mature neurons, but not neurogenesis, underlie the formation of granule cell dispersion in the epileptic hippocampus. J Neurosci 26:4701-4713. CrossRef Medline

Jacobs J, LeVan P, Chander R, Hall J, Dubeau F, Gotman J (2008) Interictal high-frequency oscillations $(80-500 \mathrm{~Hz})$ are an indicator of seizure onset areas independent of spikes in the human epileptic brain. Epilepsia 49: 1893-1907. CrossRef Medline

Jacobs J, Zijlmans M, Zelmann R, Chatillon CE, Hall J, Olivier A, Dubeau F, Gotman J (2010) High-frequency electroencephalographic oscillations correlate with outcome of epilepsy surgery. Ann Neurol 67:209-220. CrossRef Medline

Janszky J, Jokeit H, Schulz R, Hoppe M, Ebner A (2000) EEG predicts surgical outcome in lesional frontal lobe epilepsy. Neurology 54:1470-1476. CrossRef Medline

Jefferys JG, Menendez de la Prida L, Wendling F, Bragin A, Avoli M, Timofeev I, Lopes da Silva FH (2012) Mechanisms of physiological and epileptic HFO generation. Prog Neurobiol 98:250-264. CrossRef Medline

Jutila L, Immonen A, Mervaala E, Partanen J, Partanen K, Puranen M, Kälviäinen R, Alafuzoff I, Hurskainen H, Vapalahti M, Ylinen A (2002) Long term outcome of temporal lobe epilepsy surgery: analyses of 140 consecutive patients. J Neurol Neurosurg Psychiatry 73:486-494. CrossRef Medline

Khalilov I, Holmes GL, Ben-Ari Y (2003) In vitro formation of a secondary epileptogenic mirror focus by interhippocampal propagation of seizures. Nat Neurosci 6:1079-1085. CrossRef Medline

Kleen JK, Scott RC, Holmes GL, Lenck-Santini PP (2010) Hippocampal interictal spikes disrupt cognition in rats. Ann Neurol 67:250-257. CrossRef Medline

Kobayashi E, Hawco CS, Grova C, Dubeau F, Gotman J (2006) Widespread and intense BOLD changes during brief focal electrographic seizures. Neurology 66:1049-1055. CrossRef Medline

Kralic JE, Ledergerber DA, Fritschy JM (2005) Disruption of the neurogenic potential of the dentate gyrus in a mouse model of temporal lobe epilepsy with focal seizures. Eur J Neurosci 22:1916-1927. CrossRef Medline

Krook-Magnuson E, Armstrong C, Oijala M, Soltesz I (2013) On-demand optogenetic control of spontaneous seizures in temporal lobe epilepsy. Nat Commun 4:1376. CrossRef Medline

Krumholz A, Wiebe S, Gronseth GS, Gloss DS, Sanchez AM, Kabir AA, Liferidge AT, Martello JP, Kanner AM, Shinnar S, Hopp JL, French JA (2015) Evidence-based guideline: management of an Unprovoked First Seizure in Adults Report of the Guideline Development Subcommittee of the American Academy of Neurology and the American Epilepsy Society. Neurology 84:1705-1713. CrossRef Medline

Langlois M, Polack PO, Bernard H, David O, Charpier S, Depaulis A, Deransart C (2010) Involvement of the thalamic parafascicular nucleus in mesial temporal lobe epilepsy. J Neurosci 30:16523-16535. CrossRef Medline

Lantz G, Spinelli L, Seeck M, de Peralta Menendez RG, Sottas CC, Michel CM
(2003) Propagation of interictal epileptiform activity can lead to erroneous source localizations: a 128-channel EEG mapping study. J Clin Neurophysiol 20:311-319. CrossRef Medline

Ledergerber D, Fritschy JM, Kralic JE (2006) Impairment of dentate gyrus neuronal progenitor cell differentiation in a mouse model of temporal lobe epilepsy. Exp Neurol 199:130-142. CrossRef Medline

Lehmann D, Skrandies W (1980) Reference-free identification of components of checkerboard-evoked multichannel potential fields. Electroencephalogr Clin Neurophysiol 48:609-621. CrossRef Medline

Letts VA, Beyer BJ, Frankel WN (2014) Hidden in plain sight: spike-wave discharges in mouse inbred strains. Genes Brain Behav 13:519-526. CrossRef Medline

Lévesque M, Bortel A, Gotman J, Avoli M (2011) High-frequency (80-500 $\mathrm{Hz}$ ) oscillations and epileptogenesis in temporal lobe epilepsy. Neurobiol Dis 42:231-241. CrossRef Medline

Lu Y, Worrell GA, Zhang HC, Yang L, Brinkmann B, Nelson C, He B (2014) Noninvasive imaging of the high frequency brain activity in focal epilepsy patients. IEEE Trans Biomed Eng 61:1660-1667. CrossRef Medline

Matsumoto A, Brinkmann BH, Matthew Stead S, Matsumoto J, Kucewicz MT, Marsh WR, Meyer F, Worrell G (2013) Pathological and physiological high-frequency oscillations in focal human epilepsy. J Neurophysiol 110:1958-1964. CrossRef Medline

Mégevand P, Quairiaux C, Lascano AM, Kiss JZ, Michel CM (2008) A mouse model for studying large-scale neuronal networks using EEG mapping techniques. Neuroimage 42:591-602. CrossRef Medline

Menendez de la Prida LM, Staba RJ, Dian JA (2015) Conundrums of highfrequency oscillations $(80-800 \mathrm{~Hz})$ in the epileptic brain. J Clin Neurophysiol 32:207-219. CrossRef Medline

Michel CM, Lantz G, Spinelli L, De Peralta RG, Landis T, Seeck M (2004) 128-channel EEG source imaging in epilepsy: clinical yield and localization precision. J Clin Neurophysiol 21:71-83. CrossRef Medline

Mohamed A, Wyllie E, Ruggieri P, Kotagal P, Babb T, Hilbig A, Wylie C, Ying Z, Staugaitis S, Najm I, Bulacio J, Foldvary N, Lüders H, Bingaman W (2001) Temporal lobe epilepsy due to hippocampal sclerosis in pediatric candidates for epilepsy surgery. Neurology 56:1643-1649. CrossRef Medline

Moseley BD, Sinha S, Meyer FB, Marsh WR, Britton JW (2012) Long term outcomes in patients with preoperative generalized interictal epileptiform abnormalities following amygdalohippocampectomy. Epilepsy Res 99: 171-175. CrossRef Medline

Oyegbile TO, Dow C, Jones J, Bell B, Rutecki P, Sheth R, Seidenberg M, Hermann BP (2004) The nature and course of neuropsychological morbidity in chronic temporal lobe epilepsy. Neurology 62:1736-1742. CrossRef Medline

Paz JT, Davidson TJ, Frechette ES, Delord B, Parada I, Peng K, Deisseroth K, Huguenard JR (2013) Closed-loop optogenetic control of thalamus as a tool for interrupting seizures after cortical injury. Nat Neurosci 16:64-70. CrossRef Medline

Pearce PS, Friedman D, LaFrancois JJ, Iyengar SS, Fenton AA, MacLusky NJ, Scharfman HE (2014) Spike-wave discharges in adult Sprague-Dawley rats and their implications for animal models of temporal lobe epilepsy. Epilepsy Behav 32:121-131. CrossRef Medline

Pittau F, Fahoum F, Zelmann R, Dubeau F, Gotman J (2013) Negative BOLD response to interictal epileptic discharges in focal epilepsy. Brain Topogr 26:627-640. CrossRef Medline

Quairiaux C, Sizonenko SV, Mégevand P, Michel CM, Kiss JZ (2010) Functional deficit and recovery of developing sensorimotor networks following neonatal hypoxic-ischemic injury in the rat. Cereb Cortex 20: 2080-2091. CrossRef Medline

Quairiaux C, Mégevand P, Kiss JZ, Michel CM (2011) Functional development of large-scale sensorimotor cortical networks in the brain. J Neurosci 31:9574-9584. CrossRef Medline

Quiroga RQ, Nadasdy Z, Ben-Shaul Y (2004) Unsupervised spike detection and sorting with wavelets and superparamagnetic clustering. Neural Comput 16:1661-1687. CrossRef Medline

Rattka M, Brandt C, Löscher W (2013) The intrahippocampal kainate model of temporal lobe epilepsy revisited: epileptogenesis, behavioral and cognitive alterations, pharmacological response, and hippoccampal damage in epileptic rats. Epilepsy Res 103:135-152. CrossRef Medline

Riban V, Bouilleret V, Pham-Lê BT, Fritschy JM, Marescaux C, Depaulis A (2002) Evolution of hippocampal epileptic activity during the development of hippocampal sclerosis in a mouse model of temporal lobe epilepsy. Neuroscience 112:101-111. CrossRef Medline 
Richardson MP (2012) Large scale brain models of epilepsy: dynamics meets connectomics. J Neurol Neurosurg Psychiatry 83:1238-1248. CrossRef Medline

Rodgers KM, Dudek FE, Barth DS (2015) Progressive, Seizure-Like, SpikeWave Discharges Are Common in Both Injured and Uninjured SpragueDawley Rats: Implications for the Fluid Percussion Injury Model of Post-Traumatic Epilepsy. J Neurosci 35:9194-9204. CrossRef Medline

Savage N (2014) The complexities of epilepsy. Nature 511:S2-S3. CrossRef

Scharfman HE (2002) Book review: epilepsy as an example of neural plasticity. Neuroscientist 8:154-173. CrossRef Medline

Scholl EA, Dudek FE, Ekstrand JJ (2013) Neuronal degeneration is observed in multiple regions outside the hippocampus after lithium pilocarpineinduced status epilepticus in the immature rat. Neuroscience 252:45-59. CrossRef Medline

Sizonenko SV, Camm EJ, Dayer A, Kiss JZ (2008) Glial responses to neonatal hypoxic-ischemic injury in the rat cerebral cortex. Int J Dev Neurosci 26:37-45. CrossRef Medline

Spencer SS (2002) Neural networks in human epilepsy: evidence of and implications for treatment. Epilepsia 43:219-227. CrossRef Medline

Staba RJ (2012) Normal and pathologic high-frequency oscillations. In: Jasper's basic mechanisms of epilepsies [internet], Ed 4. Bethesda, MD: National Center for Biotechnology Information.

Suzuki F, Junier M-P, Guilhem D, Sørensen J-C, Onteniente B (1995) Morphogenetic effect of kainate on adult hippocampal neurons associated with a prolonged expression of brain-derived neurotrophic factor. Neuroscience 64:665-674. Medline

Tatum WO 4th (2012) Mesial temporal lobe epilepsy. J Clin Neurophysiol 29:356-365. CrossRef Medline
Téllez-Zenteno JF, Dhar R, Wiebe S (2005) Long-term seizure outcomes following epilepsy surgery: a systematic review and meta-analysis. Brain 128:1188-1198. CrossRef Medline

Terry JR, Benjamin O, Richardson MP (2012) Seizure generation: the role of nodes and networks: networks and seizure generation. Epilepsia 53:e166e169. CrossRef Medline

Twele F, Schidlitzki A, Töllner K, Löscher W (2017) The intrahippocampal kainate mouse model of mesial temporal lobe epilepsy: lack of electrographic seizure-like events in sham controls. Epilepsia Open 2:180-187. CrossRef

Van Schooneveld MM, Braun KP (2013) Cognitive outcome after epilepsy surgery in children. Brain Dev 35:721-729. CrossRef Medline

von Ellenrieder N, Pellegrino G, Hedrich T, Gotman J, Lina JM, Grova C, Kobayashi E (2016) Detection and magnetic source imaging of fast oscillations $(40-160 \mathrm{~Hz})$ recorded with magnetoencephalography in focal epilepsy patients. Brain Topogr 29:218-231. CrossRef Medline

Zattoni M, Mura ML, Deprez F, Schwendener RA, Engelhardt B, Frei K, Fritschy JM (2011) Brain infiltration of leukocytes contributes to the pathophysiology of temporal lobe epilepsy. J Neurosci 31:4037-4050. CrossRef Medline

Zelmann R, Lina JM, Schulze-Bonhage A, Gotman J, Jacobs J (2014) Scalp EEG is not a blur: it can see high frequency oscillations although their generators are small. Brain Topogr 27:683-704. CrossRef Medline

Zijlmans M, Jiruska P, Zelmann R, Leijten FS, Jefferys JG, Gotman J (2012) High-frequency oscillations as a new biomarker in epilepsy. Ann Neurol 71:169-178. CrossRef Medline 